\title{
Dlg5 Regulates Dendritic Spine Formation and Synaptogenesis by Controlling Subcellular $\mathrm{N}$-Cadherin Localization
}

\author{
Shih-Hsiu J. Wang, ${ }^{1,2 \star}$ Ivana Celic, ${ }^{1,2 \star}$ Se-Young Choi, ${ }^{1,2,3}$ Martin Riccomagno, ${ }^{1,2}$ Qiang Wang, ${ }^{1,2}$ Lu 0. Sun, ${ }^{1,2}$ \\ Sarah P. Mitchell, ${ }^{1,2}$ Valera Vasioukhin, ${ }^{4}$ Richard L. Huganir, ${ }^{1,2}$ and Alex L. Kolodkin ${ }^{1,2}$ \\ ${ }^{1}$ The Solomon H. Snyder Department of Neuroscience and ${ }^{2}$ Howard Hughes Medical Institute, Johns Hopkins University School of Medicine, Baltimore, \\ Maryland 21205, ${ }^{3}$ Department of Physiology, Seoul National University School of Dentistry, Seoul, Korea, 110-749, and ${ }^{4}$ Division of Human Biology, Fred \\ Hutchinson Cancer research Center, Seattle, Washington 98109
}

Most excitatory synapses in the mammalian brain are formed on dendritic spines, and spine density has a profound impact on synaptic transmission, integration, and plasticity. Membrane-associated guanylate kinase (MAGUK) proteins are intracellular scaffolding proteins with well established roles in synapse function. However, whether MAGUK proteins are required for the formation of dendritic spines in vivo is unclear. We isolated a novel disc large-5 $(D \lg 5)$ allele in mice, $D \lg 5^{\mathrm{LP}}$, which harbors a missense mutation in the DLG5 SH3 domain, greatly attenuating its ability to interact with the DLG5 GUK domain. We show here that DLG5 is a MAGUK protein that regulates spine formation, synaptogenesis, and synaptic transmission in cortical neurons. DLG5 regulates synaptogenesis by enhancing the cell surface localization of $N$-cadherin, revealing a key molecular mechanism for regulating the subcellular localization of this cell adhesion molecule during synaptogenesis.

Key words: dendritic spine; Dlg5; $N$-cadherin; synaptogenesis

\section{Introduction}

Dendritic spines are the main postsynaptic sites of excitatory synapses in the mammalian brain (Nimchinsky et al., 2002). Spine density, distribution, and morphology exert a profound impact on synaptic transmission, integration, and plasticity (Elston and DeFelipe, 2002; Hayashi and Majewska, 2005; Ballesteros-Yáñez et al., 2006; Knobloch and Mansuy, 2008; Spruston, 2008; Bhatt et al., 2009). Not surprisingly, alterations in spine density and morphology are associated with numerous neurological and psy-

Received March 30, 2014; revised July 26, 2014; accepted Aug. 10, 2014.

Author contributions: S.-H.J.W., I.C., R.L.H., and A.L.K. designed research; S.-H.J.W., I.C., S.-Y.C., M.R., Q.W., L.O.S., and S.P.M. performed research; V.V. and R.L.H. contributed unpublished reagents/analytic tools; S.-H.J.W., I.C., S.-Y.C., M.R., Q.W., L.O.S., S.P.M., and A.L.K. analyzed data; S.-H.J.W., I.C., and A.L.K. wrote the paper.

This work was supported by the National Institutes of Health (Grant R01 CA131047 to V.V.) and the Johns Hopkins Brain Science Institute (A.L.K. and R.L.H.). A.L.K. and R.L.H. are investigators of the Howard Hughes Medical Institute. We thank Dan Leahy for help with Dlg-5 protein domain structure evaluation; the Partners Healthcare Center for Genetics and Genomics for performing SNP analysis; the Johns Hopkins University School of Medicine Microscope Facility for assistance with EM analysis; David Ginty and Paul Worley for critically reading the manuscript; Tracy Tran, Janna Merte, Kevin Wright, Qingguang Jiang, Eleftheria Koropouli, and Joshua Jones for helpful discussions; Joshua Jones, Dontais Johnson, and Crystal Chen for technical assistance; and members of the Kolodkin laboratory for assistance throughout the course of this project.

The authors declare no competing financial interests.

Correspondence should be addressed to Dr. Alex L. Kolodkin, Johns Hopkins University School of Medicine, $725 \mathrm{~N}$. Wolfe St., 1001 PCTB725, Baltimore, MD 21205. E-mail: kolodkin@jhmi.edu.

S.-H. Wang's present address: Department of Pathology and Cell Biology, Columbia University Medical Center, New York, NY.

I.C.'s present address: Department of Biochemistry and Molecular Biology, Tulane University School of Medicine, New Orleans, LA.

*S.-H.J.W. and I.C. contributed equally to this work.

DOI:10.1523/JNEUROSCI.1280-14.2014

Copyright $\odot 2014$ the authors $\quad 0270-6474 / 14 / 3412745-17 \$ 15.00 / 0$ chiatric disorders (Irwin et al., 2000; Kaufmann and Moser, 2000; Knobloch and Mansuy, 2008; Penzes et al., 2011). A comprehensive picture of the molecular and cellular processes that initiate the formation of dendritic spines and synapses requires the identification and functional analysis of the myriad intracellular components required to orchestrate connectivity in the CNS (Lippman and Dunaevsky, 2005; Tada and Sheng, 2006; Yoshihara et al., 2009; Saneyoshi et al., 2010).

A critical early event in dendritic spine formation and synaptogenesis is the stabilization of trans-synaptic contacts mediated by cell surface proteins; these proteins include neurexins, neuroligins, ephrins, leucine-rich-repeat proteins, and cadherins (Henkemeyer et al., 2003; Craig and Kang, 2007; Arikkath and Reichardt, 2008; Kayser et al., 2008; Suzuki and Takeichi, 2008; Ko et al., 2009; de Wit et al., 2009; Siddiqui and Craig, 2011). $\mathrm{N}$-cadherin is the most abundant and widely distributed classical cadherin in the mammalian brain (Yagi and Takeichi, 2000; Togashi et al., 2002) and its critical role in dendritic spine formation has been well described. For example, in cultured hippocampal neurons, $N$-cadherin knockdown using shRNA results in a decrease in dendritic spine density (Saglietti et al., 2007). However, the intracellular mechanisms that localize $N$-cadherin to the cell surface during dendritic spine formation and synaptogenesis remain poorly understood.

MAGUK proteins are intracellular scaffolding proteins with well established roles in synapse development and function, but whether MAGUK proteins are required for the formation of dendritic spines in vivo remains unclear. Discs large homolog 5 
(DLG5) is a member of the discs large (Dlg) family of MAGUK proteins (de Mendoza et al., 2010). The size and domain organization of DLG5 are distinct from other classical Dlg family members. In addition to the PDZ (PDZ-95, Dlg, ZO-1), SH3 (Src Homology 3), and GUK (Guanylate Kinase) domains, Dlg5 also contains an N-terminal CARD (Caspase Activation and Recruitment Domain) domain, a DUF (Domain of Unknown Function) domain, and a coiled-coil domain (Nechiporuk et al., 2007). Previous work shows that DLG5 is important for the delivery and stabilization of cadherin-catenin protein complexes to the plasma membrane of epithelial cells, and loss of Dlg5 in vivo leads to disruption of adherens junctions and epithelial cell polarity in Dlg5 ${ }^{-1}$ mutant mice (Nechiporuk et al., 2007). How DLG5 might function in other cell types and organ systems is unknown.

We show here that a $D \lg 5$ allele, $D \lg 5^{\mathrm{LP}}$, reveals novel neuronal functions of this MAGUK protein. DLG5 promotes dendritic spine formation and synaptogenesis in cortical pyramidal neurons through the facilitation of $\mathrm{N}$-cadherin localization to the neuronal cell surface. The DLG5 ${ }^{\mathrm{LP}}$ mutant protein abolishes key protein domain interactions required for neuronal DLG5 function. These observations lend insight into the function of MAGUK proteins in synaptogenesis and reveal a critical molecular mechanism for regulating the subcellular localization of cell adhesion molecules during synaptogenesis.

\section{Materials and Methods}

Mutagenesis and screening. $N$-ethyl- $N$-nitrosourea mutagenesis was performed as described previously (Merte et al., 2010a; Merte et al., 2010b). Briefly, C57BL/6 (B6) male mice were injected with three doses of 100 $\mathrm{mg} / \mathrm{kg}$ body weight $\mathrm{N}$-ethyl- $\mathrm{N}$-nitrosourea to induce random mutations throughout the genome. Using a three-generation breeding scheme (Fig. $1 A$ ), we outbred the mutations into $\mathrm{C} 3 \mathrm{H} / \mathrm{Hej}(\mathrm{C} 3 \mathrm{H})$ mice and analyzed G3 mice for developmental abnormalities. Freshly dissected P5 mouse brains were fixed in $4 \%$ paraformaldehyde (Sigma) overnight and equilibrated in $30 \%$ sucrose. Sagittal sections $(150 \mu \mathrm{m})$ were cut on a Leica sliding microtome. Sections were stained with antineurofilament antibody.

Mapping. Genomic DNA from mutant lines was analyzed for a panel of 768 single nucleotide polymorphisms by Partners Healthcare Center for Genetics and Genomics. The genetic lesion responsible for hydrocephalus was mapped to a $7.3 \mathrm{Mb}$ region on chromosome 14 between rs6175633 and rs13482117 using standard linkage analysis of single nucleotide polymorphisms between $\mathrm{B} 6$ and $\mathrm{C} 3 \mathrm{H}$ mice. Additional polymorphisms within this region, D14Mit207, rs3666933, and rs30102223, were analyzed, allowing us to map the genetic lesion to a $3.1 \mathrm{Mb}$ region on chromosome 14 between D14Mit207 and rs30102223, which includes 15 protein-coding genes (Table 1). Dlg5 was identified as a candidate gene based on phenotypic similarity of our mutant to previously described $D \lg 5^{-1-}$ mice (Nechiporuk et al., 2007). We sequenced the open reading frame of $D \lg 5$ and identified a $\mathrm{T} \rightarrow \mathrm{C}$ transition in exon 26 as the genetic mutation responsible for hydrocephalus in our mutant line. D14Mit207 was analyzed by genotyping with primers TCCAACTAGTCCCCCTCTACTT and CTGTGACTATCTGTACAAGACCTGC, which produces a PCR product of 126 bp in $\mathrm{B} 6$ and $104 \mathrm{bp}$ in $\mathrm{C} 3 \mathrm{H}$ mice. rs3666933 was analyzed by genotyping with primers TTGTTTCAGCACAGCCCCAGC and TCATCCCTACATCCCCTGTCC, followed by digestion with DpnI; PCR product from $\mathrm{C} 3 \mathrm{H}$, but not $\mathrm{B} 6$ mice, can be cut with DpnI. rs30102223 was analyzed by genotyping with primers CATGACTCTCAAGGGATCCACC and ATCCAAGGACAGCTTGAAGATGC, followed by digestion with SphI; PCR product from $\mathrm{C} 3 \mathrm{H}$, but not $\mathrm{B} 6$ mice, can be cut with SphI.

Animals. All mice (Mus musculus) used in this study were housed in a $12 \mathrm{~h} \mathrm{light/dark} \mathrm{cycle} \mathrm{in} \mathrm{groups} \mathrm{of} \mathrm{2-5} \mathrm{animals} \mathrm{per} \mathrm{cage,} \mathrm{had} \mathrm{access} \mathrm{to} \mathrm{food}$ and water at libitum, and were cared for in accordance with National Institutes of Health guidelines. All research conducted was done with the approval of the Johns Hopkins University Committee on Care and Use of
Animals. Dlg5 ${ }^{\text {null/null }}$ mice (Nechiporuk et al., 2007, RRID:MGI_MGI: 3758605) and $\mathrm{N}$-Cad ${ }^{\text {flox/flox }}$ (Kostetskii et al., 2005, RRID:IMSR_JAX: 007611) have been described previously and were kept on a mixed 129/B6 background. Dlg5 ${ }^{\text {LP/LP }}$ mice were kept on a mixed B6/C3H background. Both males and females were included in all experiments. All experiments were performed blinded with respect to genotype.

Genotyping. The $\mathrm{T} \rightarrow \mathrm{C}$ transition underlying the $D \lg 5^{\mathrm{LP}}$ allele creates a restriction-enzyme-resistant polymorphism. This mutant line is genotyped by amplification of an $\sim 300$ bp fragment with primers GGCGAGTGTCACCCTGTGAG and GCCTTTCTTCCTGATATCTGGAG, followed by digestion with PvuII; only a PCR product from the wild-type allele can be cut with PvuII. Genotyping for $D \lg 5^{-1-}$ mice and $N$-cad ${ }^{\text {flox/flox }}$ mice was performed as described previously (Kostetskii et al., 2005; Nechiporuk et al., 2007).

Plasmids. The V5-DLG5 expression construct was described previously (Nechiporuk et al., 2007). This construct was modified to generate V5-DLG5mCherry by inserting the gene encoding mCherry under the control of the CMV promoter. To generate V5-DLG5(L1642P)mCherry, we used overlapping PCR with primers A: GTGAAGGTGCAGAAGGGTTCAGAGC, B: CTGGGCATTCTCATCCgGCTGCCAGGCCATC, C: GATGGCCTGGCAGCcGGATGAGAATGCCCAG, and D: TGTACTCCTGATCGATCTTCTGTGC. Constructs expressing shRNAs targeting DLG5 and also silencing-resistant DLG5 were constructed using the LEMPRA based system, as described previously (Zhou et al., 2006). shRNA directed against DLG5 was cloned into the pLLX vector using primers tAGACAGAAGTTGTGGAATT, ttcaagagaAATTCCACAACTTCTGTCTttttttggaac, tcgagttccaaaaaaAGACAGAAGTTGTGGAATT and tetcttgaaAATTCCACAACTTCTGTCTa. The silencing-resistant form of DLG5 was generated using overlapping PCR primers: A: ACGCGACCAGGTCATCTCCGAGCTG, B: CTCTCAAATTCtACgACcTCgGTCTCCCAC, C: GTGGGAGACcGAgGTcGTaGAATTTGAGAG, and D: CATGCCGGCTAGCATGCCCTGGTGA and cloning the SexAI/NheI fragment into DLG5 in the PLEMPRA vector. Small letters indicate nucleotides that were changed in DLG5 sequence to generate silencing resistant form. Constructs expressing wild-type $\mathrm{SH} 3$ domain or $\mathrm{SH} 3$ domain harboring the L1642P mutation were generated by PCR using primers atggccggccatagACCATGGGAGACAGCTTCTACATC (forward) and atgGGCGCGCCGAACTCTTGGTCCATCACGTATTTG (reverse); resulting DNA fragments were ligated upstream of the $3 \mathrm{X}$ FLAG epitopes in a pCAGGS vector. A construct expressing the GUK domain was generated by PCR using primers atggecggcctGACTCAGTGAGCCTGGCCTATCAG (forward) and atggcgcgccCTATTGTTCTTGACTGACCATGG (reverse), and the resulting DNA fragment was ligated $3^{\prime}$ to the $6 \mathrm{X}$ Myc epitopes in the pCAGGS vector. All constructs generated by PCR were verified by sequencing.

In situ hybridization. In situ hybridization was performed using standard methods. Generation of a Dlg5 riboprobe has been described previously (Nechiporuk et al., 2007).

Immunohistochemistry. Immunostaining of tissue sections were was performed using standard methods. Primary antibodies used: mouse anti-neurofilament (1:5000; Developmental Studies Hybridoma Bank, catalog \#mAb 2H3, RRID:AB_2312571), rabbit anti-Brn2 (1:500; Santa Cruz Biotechnology, catalog \#sc-28594, RRID:AB_2167382), rabbit antiCux1 (1:500; Santa Cruz Biotechnology, catalog \#sc-13024, RRID: AB_2261231), rat anti-Ctip2 (1:500; Abcam, catalog \#ab18465, RRID: AB_2064130), and rabbit anti-Tbr1 (1:500; Santa Cruz Biotechnology, catalog \#sc-48816, RRID:AB_2287060). Species-specific secondary antibodies (Invitrogen) were used at 1:500. Immunostaining of cultured neurons were performed using standard methods. Primary antibodies used were as follows: chicken anti-GFP (1:1000; Aves Laboratories, catalog \#GFP-1020, RRID:AB_10000240), guinea pig anti-vGlut1 (1:1000; Millipore, catalog \#AB5905, RRID:AB_2301751), mouse anti-PSD95 (1: 500; Millipore, catalog \#MABN68, RRID:AB_10807979), rabbit antiVGAT (1:1000; Synaptic Systems, catalog \#131 003, RRID:AB_887869), mouse anti-gephyrin (1:1000; Synaptic Systems, catalog \#147 011, RRID: AB_887717), mouse anti- $\beta$ catenin (1:100; Sigma-Aldrich, catalog \#C7207, RRID:AB_476865), mouse anti-V5 (1:500; Invitrogen, catalog \#R96025, RRID:AB_159313), and rabbit anti-DsRed (1:1000; Clontech, 
A

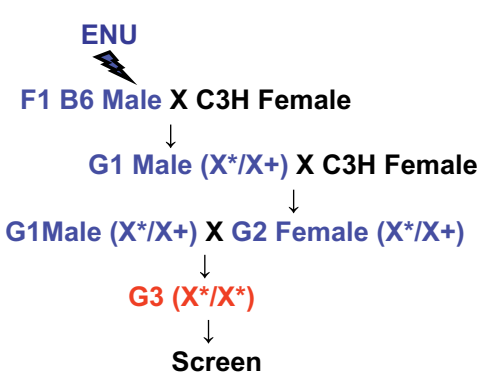

B

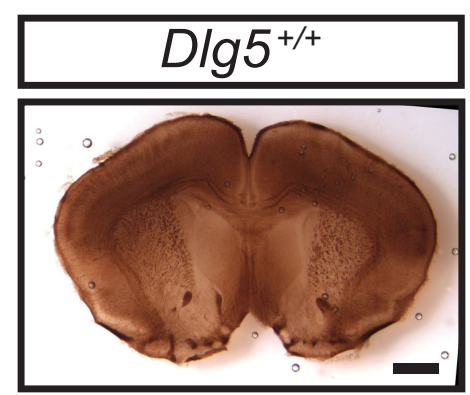

C

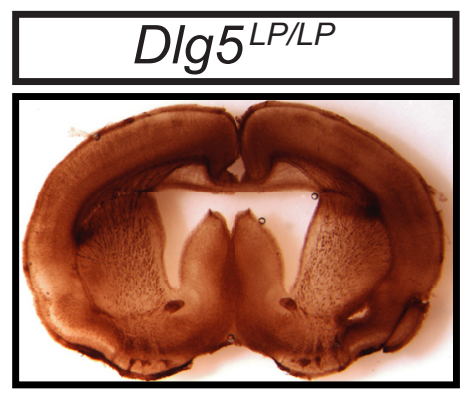

D

\section{ENSMUST00000090398}

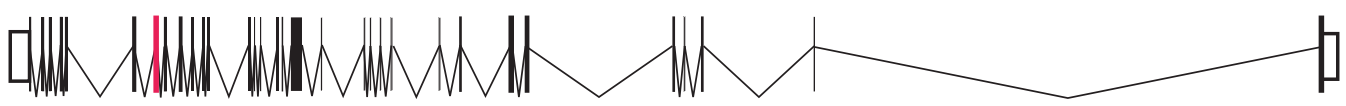

reverse strand

E

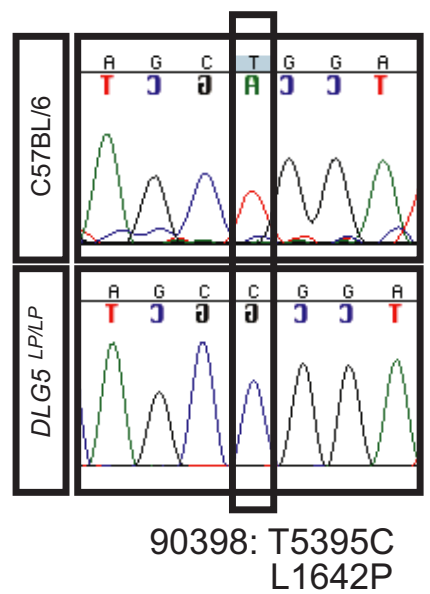

F

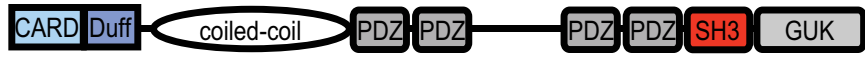

Mouse DLG5

G

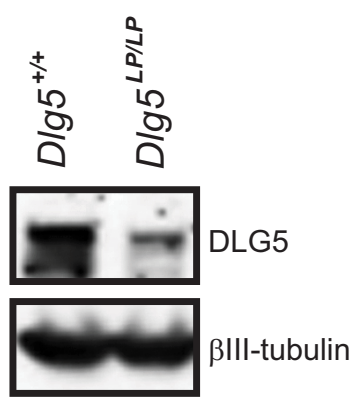

H

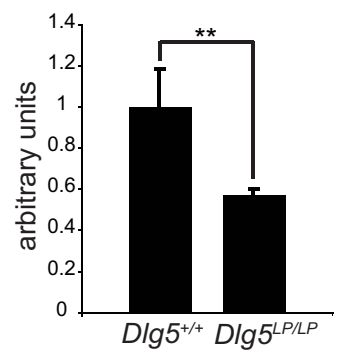

Figure 1. Isolation of the $D / g 5^{\mathrm{LP}}$ mutant mouse line. $A$, Breeding scheme for forward genetic screen to identify recessive mutations affecting mammalian brain development. $B$ - $C$, Neurofilament

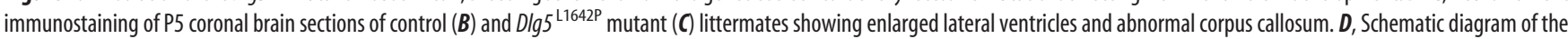
Dlg5 locus highlighting exon 26 (red), in which a single base substitution was identified in the Dlg5 mutant obtained in our genetic screen. Shown in black are coding exons from the largest predicted Dlg5 transcript, ENSMUST00000090398 (Ensembl, RRID:nif-0000 -21145). E, Primary DNA sequence data highlighting the T5395C mutation in DLG5 exon 26, resulting in the leucine ${ }^{1642}$ to proline mutation $\left(D \mid g 5^{\mathrm{LP}}\right) . \boldsymbol{F}$, Schematic diagram of the DLG5 protein. The L1642P substitution is located within the DLG5 SH3 domain. G, Western-blot analysis of DLG5 protein levels in total brain lysates prepared from Dlg $5^{+/+}$and Dlg $5^{\text {LPLP }}$ littermates revealing reduced levels of DLG5 protein in Dlg $5^{\text {LP/LP }}$ brain lysates. $\boldsymbol{H}$, Quantification of DLG5 protein levels from the total brain lysates prepared

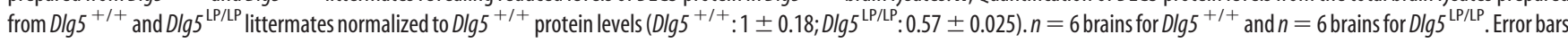
indicate SD. ${ }^{* *} p<0.01$ by two-tailed Student's $t$ test. Scale bars: $1 \mathrm{~mm}$ for $\boldsymbol{B}$ and $\boldsymbol{C}$.

catalog \#632496, RRID:AB_10013483). Species-specific secondary antibodies (Invitrogen) were used at 1:1000.

In vivo analysis of dendritic spine density. A concentrated solution of adeno-associated virus (AAV) expressing eEGFP was injected bilaterally into ventricle of postnatal day 0 (P0)-P2 mice. Dendritic spine quantification was performed on P21 brains. Animals were perfused intracardially with $4 \%$ PFA. Dissected brains were then postfixed with $4 \%$ PFA, cryoprotected with $30 \%$ sucrose, embedded in optimal cutting temperature medium, and sectioned into $100 \mu \mathrm{m}$ sections on a Leica CM3050 cryostat. Dendritic spines of layer V somatosensory cortex were visualized using immunohistochemistry with anti-GFP antibody (Aves Laboratories) detecting eEGFP.

Golgi analysis. Freshly dissected and P21 mouse brains were incubated in Golgi solution A+B (FD Rapid GolgiStain Kit; FD NeuroTechnologies) for $8 \mathrm{~d}$. After incubation, all brains were washed thoroughly with Solution $\mathrm{C}$ for $2-4 \mathrm{~d}$ at room temperature and embedded in optimal cutting temperature embedding medium. Coronal sections $(100 \mu \mathrm{m})$ through the somatosensory cortex and hippocampus were cut with a Leica CM3050 cryostat and mounted on 3\% gelatin-coated slides. Staining procedures were followed as described previously (FD NeuroTechnologies) and slides were dehydrated in ethanol, cleared in xylene, and mounted with Permount (Fisher Scientific) for microscopy. Only layer V pyramidal neurons from the somatosensory cortex were included in our analyses.

Primary neuronal cultures. The day of plug was designated embryonic day 0.5 (E0.5) for all timed pregnancies. E13.5 cortices were dissected in ice-cold L-15 Leibovitz medium (Sigma) and incubated in trypsin-EDTA $(0.05 \%$; Invitrogen $)$ at $37^{\circ} \mathrm{C}$ for $15 \mathrm{~min}$. The tissues were washed once at room temperature in $\mathrm{Ca}^{2+}$ - and $\mathrm{Mg}^{2+}$ - free HBSS (Invitrogen) and dissociated with a fire-polished glass Pasteur pipette in HBSS containing $0.025 \%$ DNase I. Dissociated cells were plated on poly-D-lysine (Sigma)coated $12 \mathrm{~mm}$ coverslips at a density of $2 \times 10^{5}$ cells per coverslip and 
Table 1. Protein-coding genes between D14Mit207 and rs30102223

\begin{tabular}{|c|c|c|}
\hline $\mathrm{CM}$ & $\begin{array}{l}\text { Genome coordinates } \\
\text { (strand) NCBI Build } 37\end{array}$ & Symbol, name \\
\hline 12.03 & $22838934-23875307(+)$ & 1700112E06Rik, RIKEN cDNA 1700112E06 gene \\
\hline 14.48 & $25441360-25448422(+)$ & 4930428N03Rik, RIKEN cDNA 4930428N03 gene \\
\hline 14.47 & $25425926-25436533(-)$ & 4930542C16Rik, RIKEN cDNA 4930542C16 gene \\
\hline 14.48 & $25436790-25440915(+)$ & 4931403M11Rik, RIKEN cDNA 4931403M11 gene \\
\hline 12.91 & $24111513-24112865(-)$ & A830039N20Rik, RIKEN cDNA A830039N20 gene \\
\hline 14.26 & $24953175-25065142(-)$ & Dlg5, discs, large homolog 5 (Drosophila) \\
\hline 14.33 & $25112436-25129188(+)$ & E330034G19Rik, RIKEN cDNA E330034G19 gene \\
\hline 12.9 & $23857416-23913793(-)$ & Gm10248, predicted gene 10248 \\
\hline 14.55 & $25728900-25732926(+)$ & Gm10398, predicted gene 10398 \\
\hline 14.31 & $25057394-25062613(-)$ & Gm17105, predicted gene 17105 \\
\hline 12.37 & $23377304-23377675(-)$ & Gm5670, predicted gene 5670 \\
\hline 14.23 & $24889296-24889859(+)$ & Gm6158, predicted gene 6158 \\
\hline 12.92 & $24117983-24622526(-)$ & $\begin{array}{l}\text { Kenma1, potassium large conductance calcium- } \\
\text { activated channel, subfamily M, alpha member } 1\end{array}$ \\
\hline 14.4 & $25267916-25306268(-)$ & $\begin{array}{l}\text { Polr3a, polymerase (RNA) III (DNA directed) } \\
\text { polypeptide A }\end{array}$ \\
\hline
\end{tabular}

grown in 24-well plates in neurobasal medium (Invitrogen) containing $2 \%$ B27 supplement (Invitrogen), $50 \mathrm{U} / \mathrm{ml}$ penicillin, $50 \mu \mathrm{g} / \mathrm{ml}$ streptomycin (Invitrogen), and $2 \mathrm{~mm}$ glutaMAX (Invitrogen) at $37^{\circ} \mathrm{C}$ with medium changes every other day. Transfection was performed at $8 \mathrm{~d}$ in vitro (DIV) with $1 \mu \mathrm{g}$ of DNA and $2 \mu \mathrm{l}$ of Lipofectamine (Invitrogen), as described in manufacturer's manual (Invitrogen). After transfection, culture medium was switched to the aforementioned medium plus $2.5 \%$ FBS (Invitrogen) and cultured for another 10-13 DIV with medium changes every other day.

In utero electroporation. In utero electroporation was performed as described previously (Tran et al., 2009). E13.5 embryos from timedpregnant CD1 female mice were injected using pLLX (control group) or DLG5 shRNA and then analyzed at P21. Dendritic spines of layer V somatosensory cortex were visualized using immunohistochemistry with anti-GFP antibody (Aves Laboratories) to detect eEGFP encoded by constructs used for electroporation.

Transmission electron microscopy. For transmission electron microscopy (TEM), P21 mice were fixed by transcardial perfusion with $3.0 \%$ formaldehyde $1.5 \%$ glutaraldehyde in $0.1 \mathrm{M} \mathrm{Na}^{+}$-cacodylate, $3 \mathrm{~mm}$ $\mathrm{Ca}^{2+}$, and 2.5\% sucrose, $\mathrm{pH}$ 7.4. Brains were dissected and the somatosensory cortex was trimmed and fixed overnight in the aforementioned fixative. The tissue was washed with $0.1 \mathrm{M} \mathrm{Na}^{+}$-cacodylate $/ 2.5 \%$ sucrose, reduced with $2 \% \mathrm{OsO}_{4}$, dehydrated in ethanol, infiltrated, and flat embedded in EPON resin. Semithin and ultrathin sections were collected using a Leica Ultracut microtome and analyzed with a Hitachi 7600 TEM. Only identified synapses on dendritic spines of layer V pyramidal neurons were included in these analyses.

Electrophysiology. Mutant mice and their wild-type littermates 3-4 weeks of age were anesthetized by isoflurane inhalation and decapitated. Brains were quickly dissected in ice-cold buffer containing the following (in mM): 212.7 sucrose, 10 glucose, $2.6 \mathrm{KCl}, 1.23 \mathrm{NaH}_{2} \mathrm{PO}_{4}, 26 \mathrm{NaHCO}_{3}$, $0.5 \mathrm{CaCl}_{2}$, and $5 \mathrm{MgCl}_{2}$. Brains were vibratome sectioned in the same solution at $300 \mu \mathrm{m}$ and transferred to normal ACSF composed of the following (in mM): $124 \mathrm{NaCl}, 5 \mathrm{KCl}, 1.23 \mathrm{NaH}_{2} \mathrm{PO}_{4}, 26 \mathrm{NaHCO}_{3}, 10$ glucose, $2 \mathrm{CaCl}_{2}$, and $1 \mathrm{MgCl}_{2}$. Slices were recovered at $30^{\circ} \mathrm{C}$ for $1 \mathrm{~h}$ and then maintained at room temperature $\left(22-25^{\circ} \mathrm{C}\right)$. Neurons were targeted for whole-cell patch-clamp recording with borosilicate glass electrodes having a resistance of 3-6 M $\Omega$. The electrode internal solution was composed of the following (in $\mathrm{mm}$ ): 130 cesium methanesulphonate, 10 HEPES, 0.5 EGTA, 8 CsCl, 5 TEA-Cl, 1 QX-314, 10 Na phosphocreatine, $0.5 \mathrm{Na}-\mathrm{GTP}$, and $4 \mathrm{Na}$-ATP. Cortical pyramidal neurons were selected from layer $\mathrm{V}$ of the posterior medial barrel subfield of primary somatosensory cortex. For AMPA receptor-mediated miniature EPSCs, external solution was supplemented with the following: $1 \mu \mathrm{M}$ tetrodotoxin, $50 \mu \mathrm{M}$ d,l-APV (2-amino-5-phosphonovalerate), and $100 \mu \mathrm{M}$ picrotoxin. Data were acquired with a Multiclamp 700A and Clampex 8 program (Molecular Devices) at $10 \mathrm{kHz}$. Before mEPSC detection and analysis, current traces were low-pass filtered at $1 \mathrm{kHz}$. mEPSCs were detected and analyzed using Mini Analysis (Synaptosoft) or Clampfit 10 program (Molecular Devices). Kinetic measurements were performed on scaled, mean EPSC traces using a monoexponential decay function. Rise times correspond to $10-90 \%$ of peak amplitude. A total of 25 wild-type neurons and 25 mutant neurons were recorded from layer $\mathrm{V} ; n=8$ animals for wildtype and $n=6$ animals for mutant animals.

Subcellular fractionation. Freshly dissected mouse brains were homogenized in ice-cold $4 \mathrm{~mm}$ HEPES, pH 7.4, $0.32 \mathrm{~m}$ sucrose, and protease inhibitors (Roche). Brain lysates were centrifuged at $2000 \times g$ for $10 \mathrm{~min}$ to give S1 (supernatant) and P1 (pellet) fractions. The S1 fraction was centrifuged at $37,000 \times g$ for $30 \mathrm{~min}$ to give S2 (supernatant) and P2 (pellet) fractions. The P2 pellet was resuspended in 4 mM HEPES and centrifuged at $82,500 \times g$ for $2 \mathrm{~h}$ in a sucrose gradient consisting of $4 \mathrm{~mm}$ HEPES plus $0.85 \mathrm{~m}, 1.0 \mathrm{M}$, and $1.2 \mathrm{~m}$ sucrose. The synaptosomal fraction was harvested at the interface between the $1.2 \mathrm{M}$ and $1.0 \mathrm{M}$ part of the gradient, centrifuged at $150,000 \times g$ for $30 \mathrm{~min}$, and resuspended in 80 $\mathrm{mm}$ Tris- $\mathrm{HCl}, \mathrm{pH}$ 7.8. To isolate postsynaptic density (PSD) fractions, synaptosomes were incubated with $40 \mathrm{~mm}$ Tris- $\mathrm{HCl}, \mathrm{pH} 8.0,0.5 \%$ Triton-X for $15 \mathrm{~min}$ on ice and then centrifuged at 32,000 $\times \mathrm{g}$ for $20 \mathrm{~min}$. The pellet was resuspended in $40 \mathrm{~mm}$ Tris- $\mathrm{HCl}, \mathrm{pH}$ 8.0, to give PSD I. The PSD I fraction was incubated again with $40 \mathrm{~mm}$ Tris- $\mathrm{HCl}, \mathrm{pH} 8.0,0.5 \%$ Triton-X for $15 \mathrm{~min}$ on ice and centrifuged at $201,800 \times g$ for $1 \mathrm{~h}$. The pellet was resuspended in $40 \mathrm{~mm}$ Tris- $\mathrm{HCl}, \mathrm{pH} 8.0$, with $0.3 \%$ SDS to give the PSD II fraction. To isolate the PSD III fraction, PSD I was incubated with $40 \mathrm{~mm}$ Tris- $\mathrm{HCl}, \mathrm{pH} 8.0,3 \%$ Sarkosyl for $15 \mathrm{~min}$ and centrifuged at $201,800 \times g$ for $1 \mathrm{~h}$. The pellet was resuspended in $40 \mathrm{~mm}$ Tris- $\mathrm{HCl}, \mathrm{pH}$ 8.0 , to give PSD III. Protein concentrations were measured by BCA assay (Pierce) and mixed in Laemmli's sample buffer. Western blot analysis was performed on $5 \mu \mathrm{g}$ of each fraction using standard methods.

Coimmunoprecipitation. For in vitro coimmunoprecipitation (co-IP) experiments, HEK293T cells were transfected using Lipofectamine 2000 (Invitrogen) according to the manufacturer's manual. Cells were lysed in RIPA lysis buffer with protease inhibitor (Roche) on ice for $30 \mathrm{~min}$. Cell lysates were precleaned with protein $\mathrm{A} / \mathrm{G}$ beads before adding rabbit anti-Myc monoclonal antibody (71D10; Cell Signaling Technology, catalog \#2278, RRID:AB_490778) for co-IP using standard methods. The co-IP of the SH3 domain was detected with mouse-anti-Flag antibody (M2; Sigma-Aldrich, catalog \#F3165, RRID:AB_259529) using standard Western blot methods. For in vivo co-IP experiments, freshly dissected mouse brains were homogenized in RIPA lysis buffer with protease inhibitor (Roche) on ice for $30 \mathrm{~min}$. Co-IP was performed using standard methods with mouse anti- $\beta$-catenin antibody $(1 \mu \mathrm{g} / 100 \mu \mathrm{g}$ of brain lysate, Sigma-Aldrich, catalog \#C7207, RRID:AB_476865) and protein A/G agarose beads (Pierce). Coimmunoprecipitated DLG5 and $\beta$-catenin were detected using standard Western blot methods.

Surface protein biotinylation assay. Cortical neurons were cultured for $21 \mathrm{DIV}$ and then incubated with $0.5 \mathrm{mg} / \mathrm{ml}$ sulfo-NHS-SS-biotin (Pierce) in PBS for $30 \mathrm{~min}$ on ice to label cell surface proteins. Unbound biotin was then quenched with $50 \mathrm{~mm}$ glycine in PBS. Cells were lysed in RIPA lysis buffer (150 mu NaCl, 1\% NP-40, 0.5\% deoxycholic acid, $0.2 \%$ SDS, $50 \mathrm{~mm}$ Tris-HCl, $\mathrm{pH}$ 8.0) with protease inhibitor (Roche) and immunocprecipitation of surface protein was performed using standard methods with streptavidin agarose beads (Pierce).

Western blot. Western blot analysis was performed using standard methods. Primary antibodies used were mouse anti-PSD95 (1:2000; Millipore, catalog \#MABN68, RRID:AB_10807979), rabbit antisynaptophysin (1:1000; Santa Cruz Biotechnology, catalog \#sc-9 116, RRID:AB_2199007), rabbit anti-GFP (1:1000; Santa Cruz Biotechnology, catalog \#sc-33150, RRID:AB_654471), mouse anti-actin (1:5000; Millipore, catalog \#CP01-1EA, RRID:AB_566293), mouse anti- $\beta$ catenin (1:100; Sigma-Aldrich, catalog \#C7207, RRID:AB_476865), mouse anti- $N$-cadherin (1:1000; Life Technologies, catalog \#333900, RRID:AB_10850887), and mouse anti-GluR1 (1:1000; Huganir laboratory). Generation of rabbit anti-Dlg5 antibody (1:2000) has been described previously (Nechiporuk et al., 2007). Species-specific secondary antibody was used at 1:5000 (Jackson ImmunoResearch). 


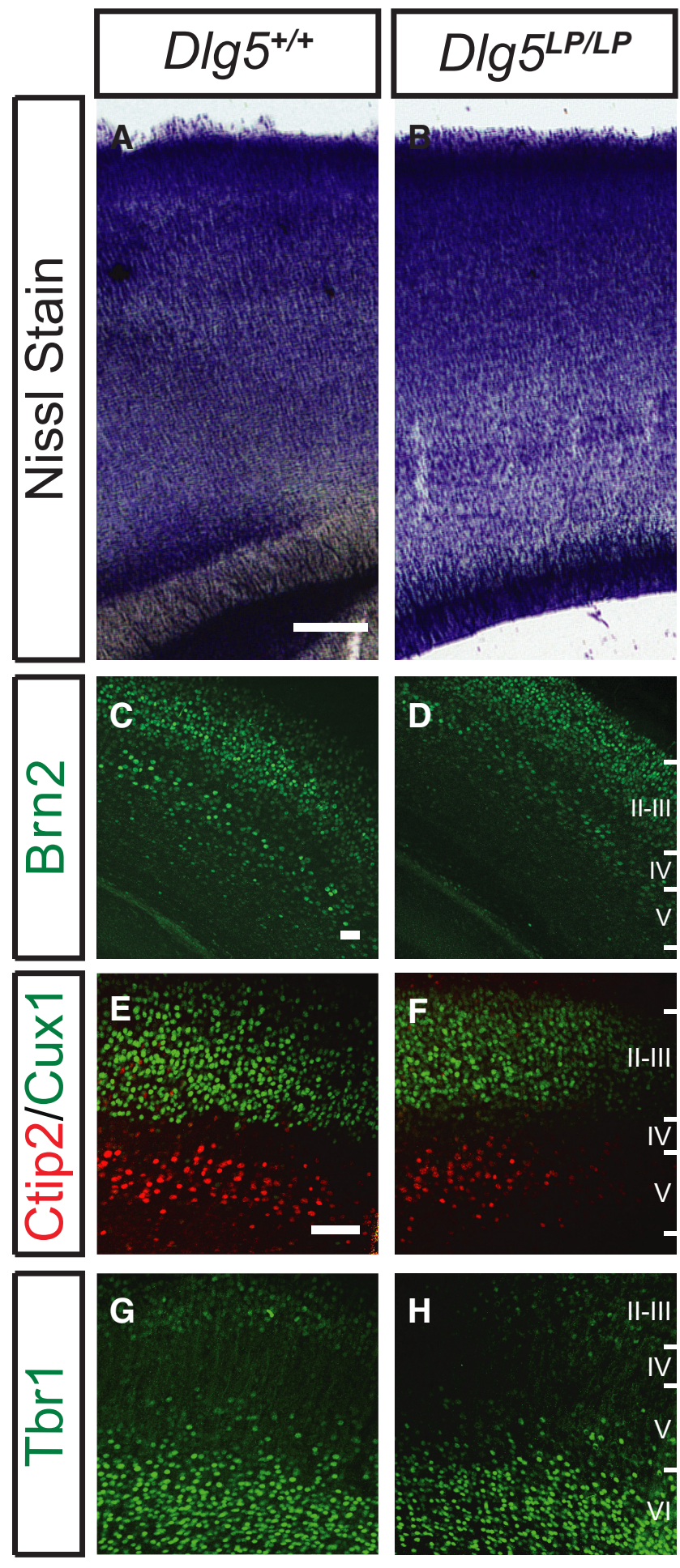

Figure 2. Cortical lamination is normal in Dlg $5^{L P / L P}$ mice. $A-B$, Nissl stain of $P 5$ brain sections from $D / g 5^{+/+}(\boldsymbol{A})$ and $D \lg 5^{\mathrm{LP} / \mathrm{LP}}(\boldsymbol{B})$ mice. $\boldsymbol{C}-\boldsymbol{H}, \mathrm{P} 5$ brain sections from Dlg $5^{+/+}(\boldsymbol{C}, \boldsymbol{E}, \boldsymbol{G})$ and $D \lg 5^{\mathrm{LP} / \mathrm{LP}}(\boldsymbol{D}, \boldsymbol{F}, \boldsymbol{H})$ mice were stained for $\operatorname{Brn} 2(\boldsymbol{C}, \boldsymbol{D})$, Cux1 and Ctip2 $(\boldsymbol{E}, \boldsymbol{F})$, and $\operatorname{Tbr} 1(\boldsymbol{G}, \boldsymbol{H})$. $D l g 5^{\text {LP/LP }}$ mice exhibit apparently normal cerebral cortical lamination. Scale bars: $100 \mu \mathrm{m}$ for $A$ and $\boldsymbol{B} ; 50 \mu \mathrm{m}$ for $\boldsymbol{C}, \boldsymbol{D}, \boldsymbol{E}-\boldsymbol{H}$.

\section{Results}

A forward genetic screen identifies a novel Dlg5 allele

Using a three-generation forward genetic screen for recessive mutations affecting murine brain development (Fig. 1A; Merte et al., 2010a; Merte et al., 2010b), we identified a mutant mouse line that exhibits severely enlarged ventricles (Fig. 1B,C). We mapped
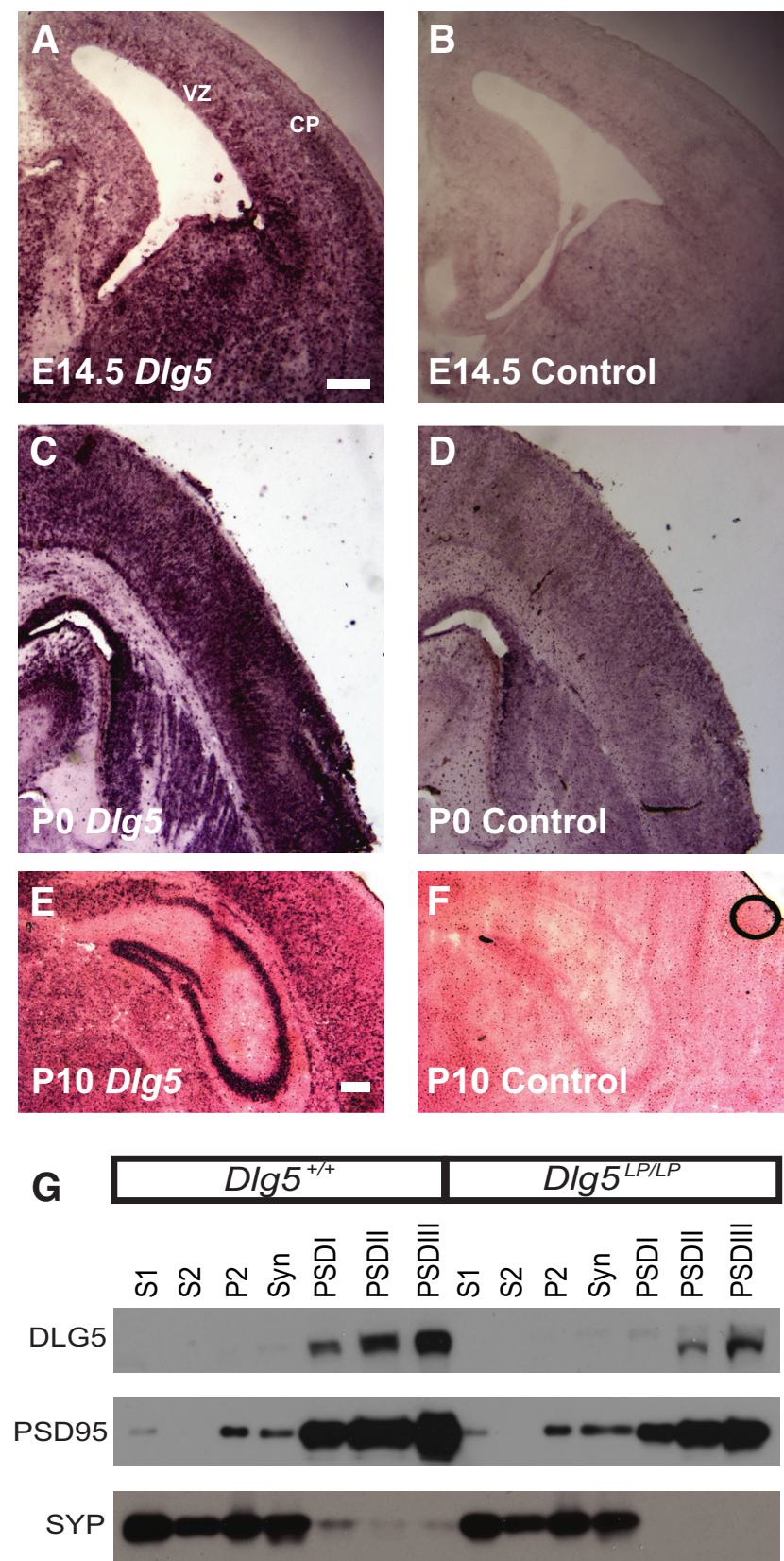

Figure 3. $D \lg 5$ Is expressed in the postnatal brain and enriched in postsynaptic density fractions. $\boldsymbol{A}-\boldsymbol{F}$, In situ hybridization for $D \lg 5$ on brain sections from E14.5 $(\boldsymbol{A}, \boldsymbol{B}), \mathrm{PO}(\boldsymbol{C}, \boldsymbol{D})$, and P10 $(\boldsymbol{E}, \boldsymbol{F})$ wild-type (WT) mice. Robust expression of Dlg5 is observed in the ventricular zone (VZ) and cortical plate (CP) at E14.5, cortex and striatum at PO, and cortex and hippocampus at P10. $\boldsymbol{A}, \boldsymbol{C}, \boldsymbol{E}$ show the antisense probe; $\boldsymbol{B}, \boldsymbol{D}$, and $\boldsymbol{F}$ the sense probe (black circle in $\boldsymbol{F}$ is a bubble on slide). G, Subcellular fractionation of $P 21$ mouse forebrains was performed to generate fractions progressively enriched in synaptic membranes, as verified by immunoblotting for PSD-95 and synaptophysin. DLG5 protein is highly enriched in PSD fractions. DLG5 ${ }^{\mathrm{LP}}$ protein is also enriched

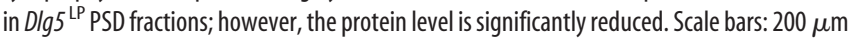
for $\boldsymbol{A}-\boldsymbol{D} ; 200 \mu \mathrm{m}$ for $\boldsymbol{E}$ and $\boldsymbol{F}$.

the genetic lesion underlying this brain defect to a $3.1 \mathrm{Mb}$ interval on chromosome 14 between D14Mit207 and rs30102223 that contains 15 protein-coding genes (Table 1). We identified Dlg5 as a candidate gene harboring this genetic lesion based on the phenotypic similarity between this mutant and a previously described $D \lg 5^{-1-}$ mouse mutant (Nechiporuk et al., 2007). We sequenced the open reading frame of $D \lg 5$ and identified a $\mathrm{T} \rightarrow \mathrm{C}$ transition in exon 26 that results in a L1642P missense mutation 

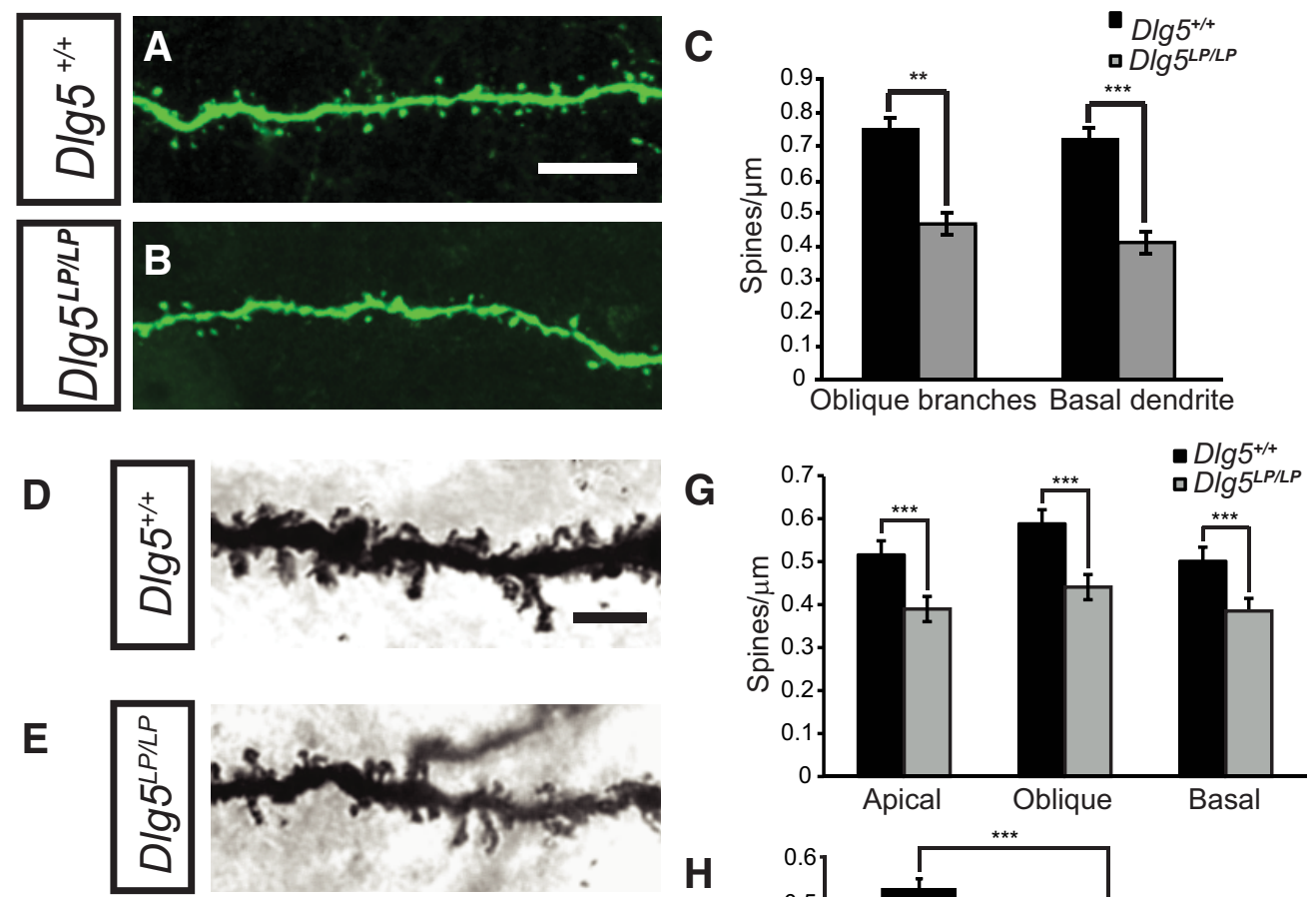

H
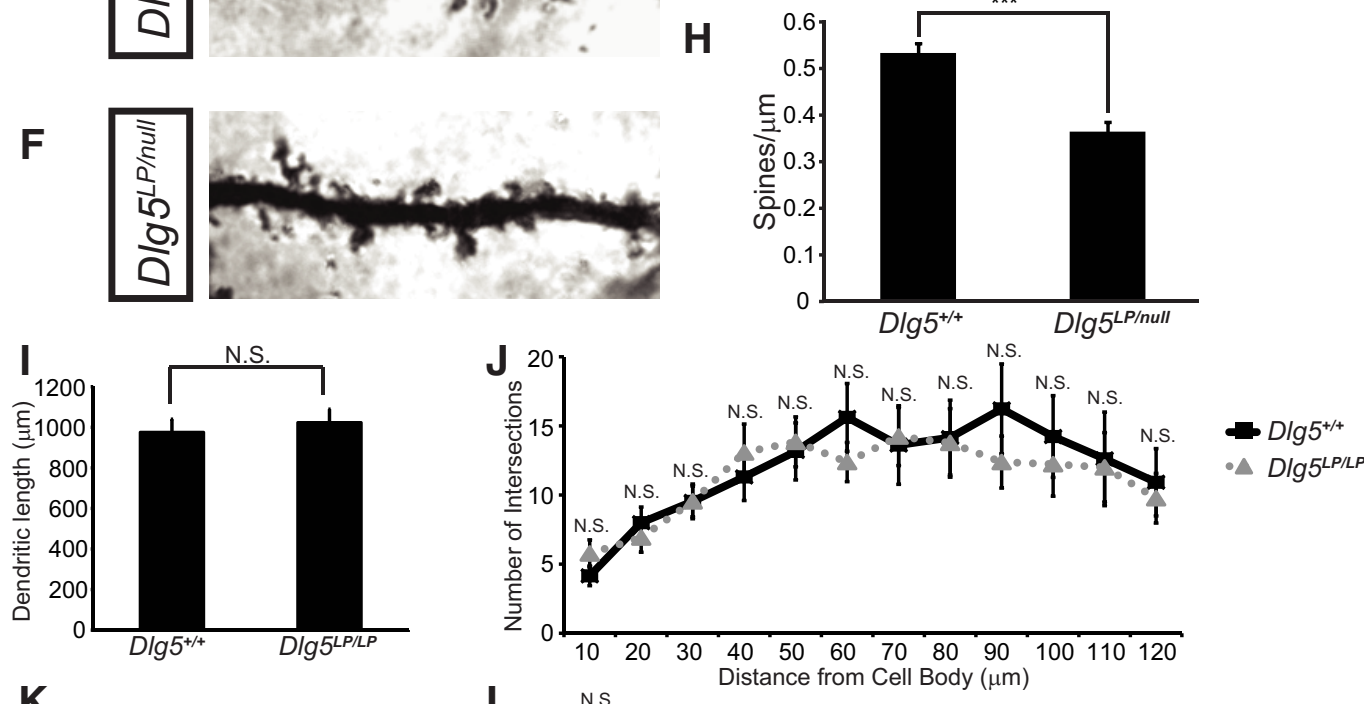

\section{K}

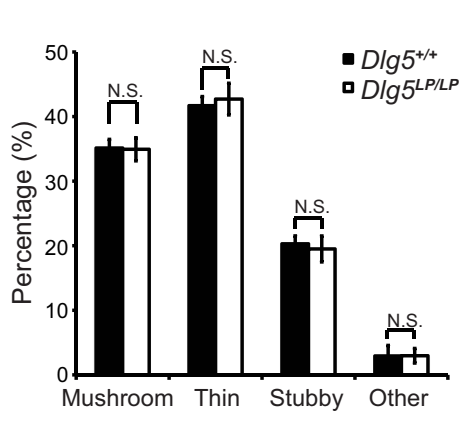

$\mathbf{L}$

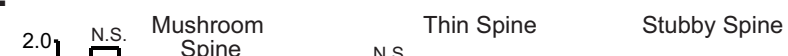

Figure 4. DLG5 regulates dendritic spine density in layer V cortical pyramidal neurons in vivo. $A, B$, Layer V pyramidal neurons from P21 Dlg $5^{+/+}(\boldsymbol{A})$ and Dlg $5^{\text {LP/LP }}(\boldsymbol{B})$ brains were labeled using GFP-expressing AAV. Dlg5 $5^{\text {LP/LP }}$ neurons show a significant reduction in dendritic spine density. C, Quantification of dendritic spine density in layer V pyramidal neurons (Dlg5 ${ }^{+/+}$side branches:

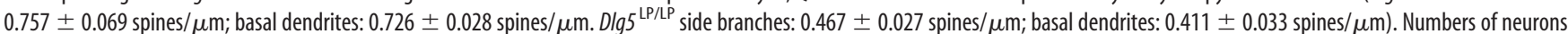
quantified: $n=8$ neurons from 3 brains for Dlg $5^{+/+} ; n=15$ neurons for oblique branches of the apical dendrite and $n=10$ for basal dendrites from 5 brains for Dlg $5^{\text {LP/LP }}$. Error bars indicate SEM. ${ }^{* *} p<0.01$ and ${ }^{* * *} p<0.001$ by two-tailed Student's t test. $\boldsymbol{D}-\boldsymbol{F}$, Layer V pyramidal neurons from Dlg $5^{+/+}(\boldsymbol{D}), D \operatorname{Dlg} 5^{\mathrm{LP} / \mathrm{LP}}(\boldsymbol{E})$, and $D \lg 5^{\mathrm{LP} / \text { null }}(\boldsymbol{F})$ brains were examined using Golgi staining at P21. $D / g 5^{\mathrm{LP} / \mathrm{P} P}$ and Dlg $5^{\mathrm{LP} / \text { null }}$ neurons show a significant reduction in dendritic spine density. G, Quantification of dendritic spine density in layer V pyramidal neurons (Dlg $5^{+/+}$apical dendrite: $0.516 \pm$ 0.033 spines $/ \mu \mathrm{m}$; side branches: $0.588 \pm 0.033$ spines $/ \mu \mathrm{m}$; basal dendrites: $0.501 \pm 0.030$ spines $/ \mu \mathrm{m}$. Dlg $5^{\text {LP/LP }}$ apical dendrite: $0.39 \pm 0.029$ spines $/ \mu \mathrm{m} ;$ side branches: $0.441 \pm 0.029$ spines $/ \mu \mathrm{m}$; basal dendrites: $0.385 \pm 0.034$ spines $/ \mu \mathrm{m}$ ). Numbers of neurons quantified: $n=80$ neurons from 5 brains for $D 15^{+/+} ; n=80$ neurons from 6 brains for $D l g 5^{\text {LP } / \mathrm{LP}}$. Error bars indicate SEM. ${ }^{* * *} p<0.001$ by two-tailed Student's $t$ test. $\boldsymbol{H}$, Quantification of dendritic spine density in layer V pyramidal neurons (Dlg $5^{+/+}$apical dendrite: $0.532 \pm 0.021$ spines $/ \mu \mathrm{m} ; D / g 5^{\text {LP/ null }}$ apical dendrite: $0.364 \pm 0.021$ spines $/ \mu \mathrm{m}$ ). Number of neurons quantified: $n=15$ neurons from 3 brains for $D l g 5^{+/+} ; n=15$ neurons from 3 brains for Dlg $5^{\text {LP/null }}$. Error bars indicate SEM. ${ }^{* * *} p<0.001$ by two-tailed Student's $s$ test. I, Quantification of total dendritic length in layer V pyramidal neurons (Dlg $5^{+/+}: 974.53 \pm 65.41 \mu \mathrm{m} ;$ Dlg $\left.5^{\text {LP/LP }}: 1022.52 \pm 66.76 \mu \mathrm{m}\right)$. (Figure legend continues.) 
in the evolutionarily conserved SH3 domain of the DLG5 protein (Fig. $1 D-F$ ). We designate this novel $D \lg 5$ allele $D \lg 5^{\mathrm{LP}}$. The severity of hydrocephalus in $D \lg 5^{\mathrm{LP} / \mathrm{LP}}$ mice is equivalent to that observed in Dlg $5^{\text {null/null }}$ mice (Nechiporuk et al., 2007). This suggests that the $D \lg 5^{\mathrm{LP}}$ mutant is either a null or a very strong hypomorphic allele of Dlg5. Western blot analysis shows that DLG5 ${ }^{\mathrm{LP}}$ protein is present in $D \lg 5^{\mathrm{LP} / \mathrm{LP}}$ mutant brains at $\sim 50 \%$ of wild-type DLG5 levels (Fig. $1 G, H$ ). Although $D \lg 5^{\mathrm{LP} / \mathrm{LP}}$ mutants exhibit enlarged ventricles, cortical lamination appears normal in these mutants, as revealed by Nissl staining and immunostaining for the cortical layer markers BRN2 (layer II/III, V), CUX1 (layer II/III), CTIP2 (layer V), and TBR1 (layer II/III, VI; Fig. 2).

\section{DLG5 is expressed in the postnatal murine brain}

Previous work shows that the hydrocephalus phenotype observed in $D \lg 5^{-1-}$ mice is caused by disruption of adherens junctions and loss of cell polarity in ventricular epithelial cells, resulting in abnormal closure of the cerebral aqueduct (Nechiporuk et al., 2007). To determine whether DLG5 functions during neural development, we first analyzed $D \lg 5$ expression in the brain using in situ hybridization. We observed strong expression of Dlg5 mRNA in the cortical plate at E14.5 (Fig. 3A,B). By P0, Dlg5 mRNA becomes widely expressed in various regions of the brain, including the cortex, striatum (Fig. $3 C, D$ ), dorsal thalamus, and cerebellum (data not shown). Dlg5 mRNA expression levels in cortical neurons remain high at P10 (Fig. 3E,F) and gradually decrease after P21 (data not shown).

To further define DLG5 protein localization, we performed subcellular fractionation of P21 brains to enrich for postsynaptic densities (PSDs), verifying the fidelity of our isolation by immunoblotting for the presynaptic and postsynaptic markers synaptophysin and PSD95, respectively. DLG5 is highly enriched in PSD fractions in wild-type brains and the mutant DLG5 ${ }^{\mathrm{LP}}$ protein, though present at lower levels than wild-type, retains its localization in the PSD fraction (Fig. $3 G$ ). These results show that DLG5 is a PSD component and that it is included in the PSD core protein-containing detergent-insoluble PSDIII fraction.

\section{$\leftarrow$}

(Figure legend continued.) There is no significant difference in total dendritic length. Number of neurons quantified: $n=13$ neurons from 5 brains for $D l g 5^{+/+} ; n=13$ neurons from 5 brains for Dlg5 ${ }^{\text {LP/LP }}$. Error bars indicate SEM. N.S. $p=0.612$ by two-tailed Student's $t$ test. J, Sholl analysis of layer $V$ pyramidal neuron basal dendritic arbors shows no significant difference in dendritic complexity. Number of neurons quantified: $n=13$ neurons from 5 brains for $D l g 5^{+/+} ; n=13$ neurons from 5 brains for Dlg $5^{\text {LP/LP }}$. Error bars indicate SEM. N.S. $p>0.05$ by two-tailed Student's $t$ test. $\boldsymbol{K}$, Percentage of different classes of spines ( $\left(\mathrm{lg} 5^{+/+}\right.$mushroom spine: $35.1 \pm 1.3 \%$, thin spine: $41.7 \pm 1.4 \%$, stubby spine: $20.3 \pm 1.2 \%$, others: $2.9 \pm 1.6 \%$; Dlg $5^{\text {LP/LP }}$ mushroom spine: $34.9 \pm 1.8 \%$, thin spine: $42.7 \pm 2.5 \%$, stubby spine: $19.5 \pm 2.0 \%$, others: $2.9 \pm 1.1 \%)$. There is no significant difference in the percentage of different classes of spines. Number of neurons quantified: $n=15$ neurons from 5 brains for $\mathrm{Dlg}^{+/+} ; n=15$ neurons from 5 brains for Dlg5 ${ }^{\text {LP/LP }}$. Error bars indicate SEM. N.S. $p>0.05$ by two-tailed Student's $t$ test. $L$, Morphologic analysis of different classes of spines $\left(D l g 5^{+/+}\right.$mushroom spine length: $1.803 \pm 0.058 \mu \mathrm{m}$, head diameter: $1.365 \pm 0.069 \mu \mathrm{m}$, neck width: $0.618 \pm$ $0.030 \mu \mathrm{m}$, thin spine length: $1.670 \pm 0.063 \mu \mathrm{m}$, head diameter: $0.683 \pm 0.032 \mu \mathrm{m}$, neck width: $0.592 \pm 0.029 \mu \mathrm{m}$, stubby spine length: $1.073 \pm 0.077 \mu \mathrm{m}$, head diameter: $1.285 \pm$ $0.101 \mu \mathrm{m}$; Dlg5 $5^{\text {LP/LP }}$ mushroom spine length: $1.654 \pm 0.051 \mu \mathrm{m}$, head diameter: $1.329 \pm$ $0.051 \mu \mathrm{m}$, neck width: $0.602 \pm 0.025 \mu \mathrm{m}$, thin spine length: $1.627 \pm 0.052 \mu \mathrm{m}$, head diameter: $0.739 \pm 0.028 \mu \mathrm{m}$, neck width: $0.617 \pm 0.021 \mu \mathrm{m}$, stubby spine length: $1.049 \pm$ $0.061 \mu \mathrm{m}$, head diameter: $1.159 \pm 0.078 \mu \mathrm{m})$. Number of spines quantified: $n=56$ mushroom spines, 67 thin spines, and 33 stubby spines from 15 neurons from 5 brains for $D l g 5^{+/+}$; $n=53$ mushroom spines, 71 thin spines, and 31 stubby spines from 15 neurons from 5 brains for Dlg $5^{\text {LP/LP. }}$. Error bars indicate SEM. N.S. $p>0.05$ by two-tailed Student's t test. Scale bars: 10 $\mu \mathrm{m}$ for $\boldsymbol{A}$ and $\boldsymbol{B}, 5 \mu \mathrm{m}$ for $\boldsymbol{D}-\boldsymbol{F}$.

\section{DLG5 regulates dendritic spine density in vivo}

The strong expression of $D \lg 5$ in the cerebral cortex during early postnatal development and the localization of DLG5 in PSD fractions raise the possibility that DLG5 may function in cortical neurons. To determine whether DLG5 regulates dendritic spine development in vivo, we used GFP-expressing AAV to label and analyze dendritic spine morphology in P21 cortical pyramidal neurons, focusing our analysis on the somatosensory cortex. $D \lg 5^{\mathrm{LP} / \mathrm{LP}}$ layer V pyramidal neurons exhibit a $38 \%$ and $44 \%$ reduction in dendritic spine density along oblique branches of primary apical dendrites and basal dendrites, respectively (Fig. $4 A-C)$. This reduction in spine density is not restricted to specific dendritic regions, nor do we observe abnormalities in spine morphology. In a parallel approach, we examined dendritic spine morphology in P21 cortical pyramidal neurons using Golgi staining. Consistent with results obtained using AAV-GFP labeling, we observed a significant reduction in dendritic spine density along the primary apical dendrites, oblique branches of apical dendrites, and basal dendrites of $D \lg 5^{\mathrm{LP} / \mathrm{LP}}$ layer $\mathrm{V}$ pyramidal neurons (Fig. $4 D, E, G$ ).

To confirm that the $D \lg 5^{\mathrm{LP}}$ point mutation is the genetic lesion underlying the dendritic spine density phenotype we observed, we performed a complementation test by breeding $D \lg 5^{\text {LP/LP }}$ mice to D $\lg 5^{\text {null/null }}$ mice (Nechiporuk et al., 2007). Dlg5 ${ }^{\mathrm{LP} / \text { null }}$ layer $\mathrm{V}$ pyramidal neurons show a significant decrease in dendritic spine density (Fig. $4 D, F, H$ ). The lack of complementation between $D \lg 5^{\mathrm{LP}}$ and $D \lg 5^{\text {null }}$ alleles shows that the decrease in dendritic spine density is indeed caused by the $D \lg 5^{\mathrm{LP}}$ mutation and not by other, as yet uncharacterized, mutations in the $D \lg 5^{\mathrm{LP} / \mathrm{LP}}$ mouse genome.

In contrast to the reduction in dendritic spine density in Dlg5 mutant mice, we did not observe significant defects in total dendritic length (Fig. 4I), basal dendrite complexity (Fig. 4J), or dendritic spine morphology (Fig. $4 K, L$ ) in Dlg $5^{\mathrm{LP} / \mathrm{LP}}$ and Dlg $5^{\text {null/null }}$ mice (data not shown). These findings suggest that DLG5 regulates dendritic spine formation without affecting other aspects of dendritic development and spine morphogenesis.

\section{DLG5 regulates dendritic spine development cell autonomously}

To eliminate the possibility that reduction in dendritic spine density is a secondary consequence of enlarged ventricles, we next examined dendritic spine density in cultured cortical pyramidal neurons. Cortical neurons were derived from E13.5 embryos, transfected with a DNA construct expressing GFP at 8 DIV to visualize dendritic spines, and then cultured for a total of 18 DIV. Enlargement of the lateral ventricles is not observed in Dlg5 mutants at E13.5, the developmental time point when cortical neurons are dissected from the mouse embryo and placed in culture (data not shown). Consistent with our in vivo observations, Dlg5 ${ }^{\mathrm{LP} / \mathrm{LP}}$ pyramidal neurons in vitro show a $25 \%$ reduction in spine density (Fig. 5A-C). These results strongly suggest that the Dlg5 ${ }^{\mathrm{LP} / \mathrm{LP}}$ dendritic spine phenotype we observed in vivo does not result from the progressive enlargement of lateral ventricles that occurs in these mutants or from any other defects associated with $D \lg 5^{\mathrm{LP}}$. Furthermore, $D \lg 5^{\text {null/null }}$ pyramidal neurons in vitro also show a $25 \%$ reduction in spine density (Fig. $5 D-F$ ), equivalent to that observed in $D \lg 55^{\mathrm{LP} / \mathrm{LP}}$ neurons. This confirms that the $D \lg 5^{\mathrm{LP}}$ mutant is a null, or very strong loss-of-function, Dlg5 allele.

The enrichment of the DLG5 protein in PSD fractions raises the possibility that DLG5 functions cell autonomously in postsynaptic neurons to regulate dendritic spine formation and synaptogenesis. To test this idea, we designed shRNA constructs that 

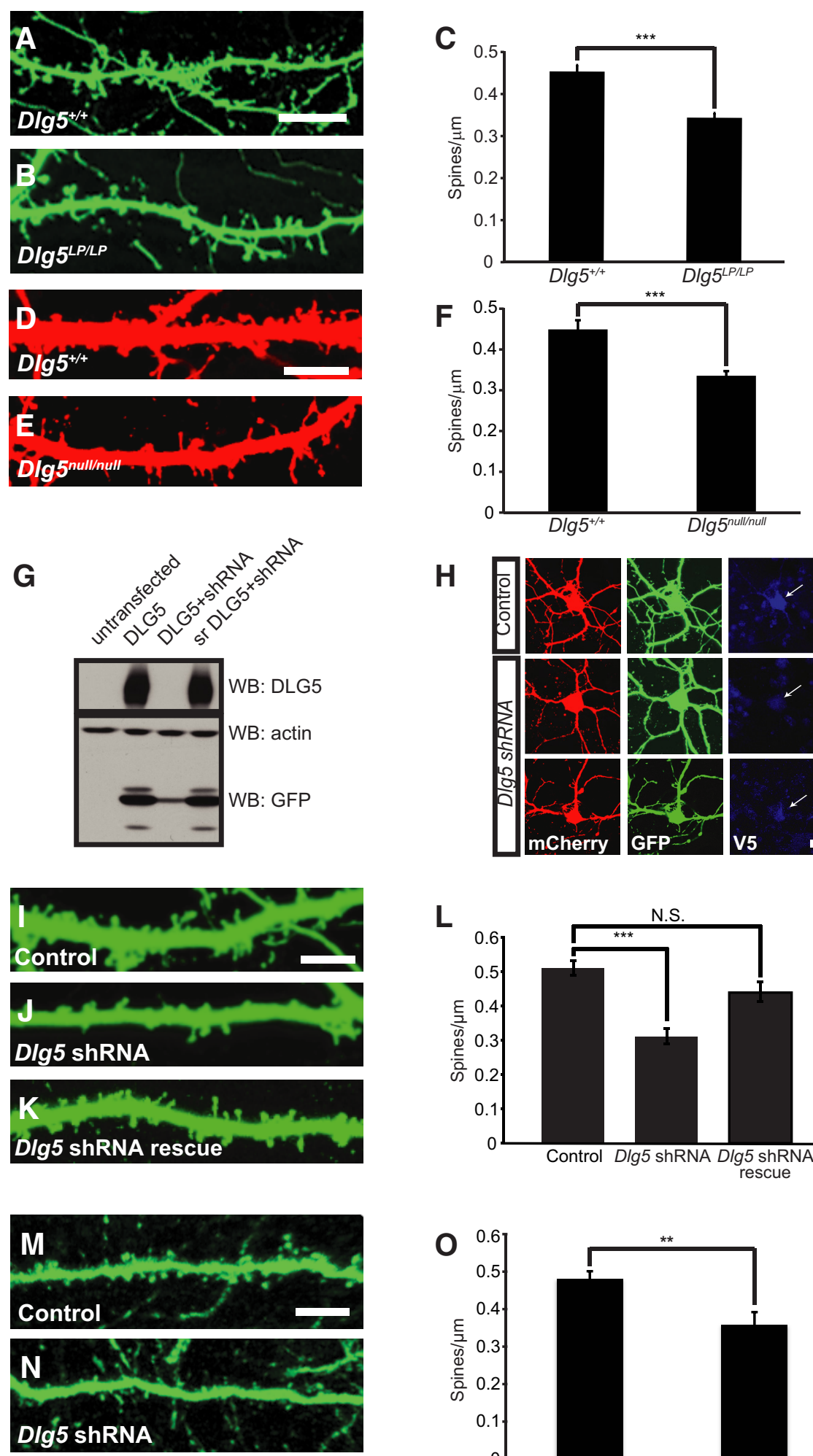

H
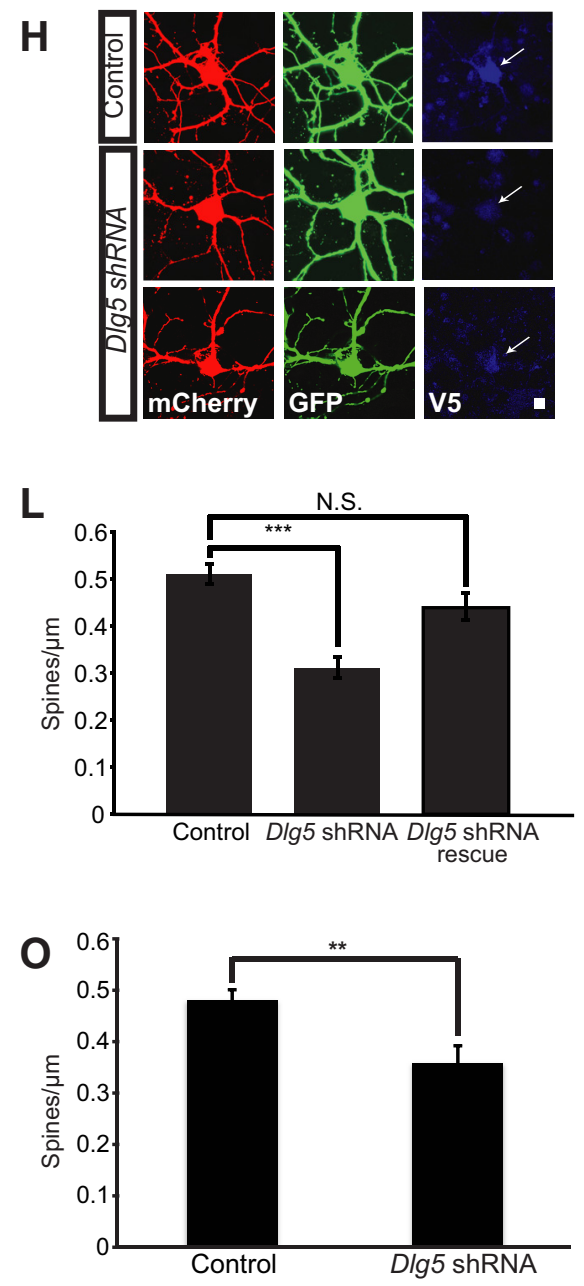

Figure 5. DLG5 regulates dendritic spine density cell autonomously. $A, B$, Cortical neurons derived from E13.5 Dlg $5^{+/+}(\boldsymbol{A})$ and $D \operatorname{Dlg} 5^{\text {LPLP }}(\boldsymbol{B})$ embryos were cultured for 8 DIV, transfected with a GFP-expressing construct to visualize dendritic spines, and cultured for a total of $18 \mathrm{DIV}$. DIg $5{ }^{\mathrm{LP} / L \mathrm{P}}$ cortical neurons with pyramidal morphology show a significant reduction in dendritic spine density in vitro. C, Quantification of dendritic spine density in cultured cortical neurons at 18 DIV (Dlg $5^{+/+}: 0.454 \pm 0.015$ spines $/ \mu \mathrm{m} ; D / g 5^{L P / L P}: 0.345 \pm 0.011$ spines $\left./ \mu \mathrm{m}\right)$. Number of neurons quantified: $n=39$ neurons from 3 independent cultures for $D l g 5^{+/+}$, and $n=60$ neurons from 3 independent cultures for Dlg $5^{\text {LP LP }}$. Error bars indicate SEM. ${ }^{* * *} p<0.001$ by two-tailed Student's $t$ test. $\boldsymbol{D}, \boldsymbol{E}$, Cortical neurons derived from E13.5 Dlg $5^{+/+} \boldsymbol{D}$, and $D / g 5^{\text {null/null }} \boldsymbol{E}$, embryos were transfected with GFP at 8 DIV to visualize dendritic spines and cultured for a total of 18 DIV. Dlg $5^{-1-}$ mutant neurons show a significant reduction in dendritic spine density. $F$, Quantification of dendritic spine density in cultured cortical neurons at $18 \mathrm{DIV}$ ( DIg $5^{+/+}: 0.449 \pm 0.022$ reduce DLG5 protein to nearly undetectable levels in HEK293T cells (Fig. 5G) and also in cultured cortical neurons (Fig. $5 H)$. Wild-type cortical neurons derived from E13.5 embryos were transfected with Dlg5 shRNA at 8 DIV and cultured for a total of 18-21 DIV. shRNA knockdown of Dlg5 causes a 39\% reduction in dendritic spine density (Fig. 5I,J,L). To eliminate the possibility of D $\lg 5$ shRNA off-target effects, we designed a construct that expresses an shRNA silencing-resistant Dlg5 together with the $D \lg 5$ shRNA (Fig. 5G). Cortical neurons transfected with this rescue construct show wild-type dendritic spine densities (Fig. 5I,K,L), confirming that the shRNA phenotype we observe is indeed caused by DLG5 loss-of-function.

To assess cell autonomous DLG5 requirements in vivo, we performed in utero

\footnotetext{
spines $/ \mu \mathrm{m} ; D \lg 5^{\text {null/null: }} 0.336 \pm 0.011$ spines $\left./ \mu \mathrm{m}\right)$. Number of neurons quantified: $n=20$ neurons from 3 independent cultures for Dlg $5^{+/+}$, and $n=20$ neurons from 3 independent cultures for Dlg $5^{\text {null/null }}$. Error bars indicate SEM. ${ }^{* * *} p<0.001$ by two-tailed Student's $t$ test. $\mathbf{G}$, Western-blot analysis of whole-cell extracts prepared from HEK293T cells transfected with constructs expressing GFP-IRES-Dlg5, shRNA targeting Dlg5 and a silencing resistant Dlg5 shRNA (srDLG5). Immunoblotting with DLG5 antibody demonstrates efficient reduction in DLG5 protein levels in extracts prepared from cells transfected with the Dlg5 shRNA construct and no reduction after transfection with srDLG5. Actin provides the loading control. $\boldsymbol{H}$, Cortical neurons derived from E13.5 embryos were transfected with constructs expressing GFP and V5-Dlg5$m$ Cherry, or GFP, Dlg5 shRNA and V5-Dlg5-mCherry, at 8 DIV and cultured for a total of 18 DIV. Immunostaining for V5 (blue) shows efficient reduction in DLG5 protein levels in neurons transfected with DIg5 shRNA. $\boldsymbol{I}-\boldsymbol{K}$, Cortical neurons derived from E13.5 wild-type embryos were transfected with constructs expressing GFP (I), Dlg5 shRNA (I), and $\operatorname{srDlg} 5(\boldsymbol{K})$ at 8 DIV and cultured for a total of $18-21$ DIV. Dlg5 knockdown with Dlg5 shRNA resulted in a significant reduction in dendritic spine density, which was suppressed by srDlg5. L, Quantification of dendritic spine density in cultured cortical neurons at $18-21$ DIV. (GFP: $0.455 \pm 0.029$ spines $/ \mu \mathrm{m}$; Dlg 5 shRNA and GFP: $0.257 \pm 0.024$ spines $/ \mu \mathrm{m}$; srDlg5 shRNA and GFP: $0.417 \pm 0.024$ spines $/ \mu \mathrm{m})$. Number of neurons quantified: $n=15$ neurons from 3 independent cultures for GFP, $n=15$ neurons from 3 independent cultures for Dlg 5 shRNA, and $n=$ 16 neurons from 3 independent cultures for Dlg 5 shRNA rescue. Error bars indicate SEM. ${ }^{* * *} p<0.001$ and N.S. $p=0.313$ by two-tailed Student's test. $M, N$, Layer V cortical neurons of wild-type mice were sparsely transfected with GFP $(\boldsymbol{M})$ or Dlg5 shRNA ( $\boldsymbol{N}$ ) by in utero electroporation at E13.5 and analyzed by GFP immunostaining at P21. Dlg5 knockdown using shRNA resulted in a significant reduction in dendritic spine density in vivo. 0, Quantification of dendritic spine density in cortical neurons labeled by in utero electroporation at P21 (GFP: $0.481 \pm 0.02$ spines $/ \mu \mathrm{m}$. Dlg 5 shRNA: $0.359 \pm 0.033$ spines $/$ $\mu \mathrm{m})$. Number of neurons quantified: $n=10$ neurons for GFP, and $n=10$ neurons for Dlg5 shRNA. Error bars indicate SEM. ${ }^{* *} p<0.01$ by two-tailed Student's $t$ test. Scale bar in $10 \mu \mathrm{m}$ for $\boldsymbol{A}$ and $\boldsymbol{B}, 7.5 \mu \mathrm{m}$ for $\boldsymbol{D}$ and $\boldsymbol{E}, 10 \mu \mathrm{m}$ for $\boldsymbol{I} \boldsymbol{K} \boldsymbol{K}$, and $10 \mu \mathrm{m}$ for $\boldsymbol{M}$ and $\boldsymbol{N}$.
} 

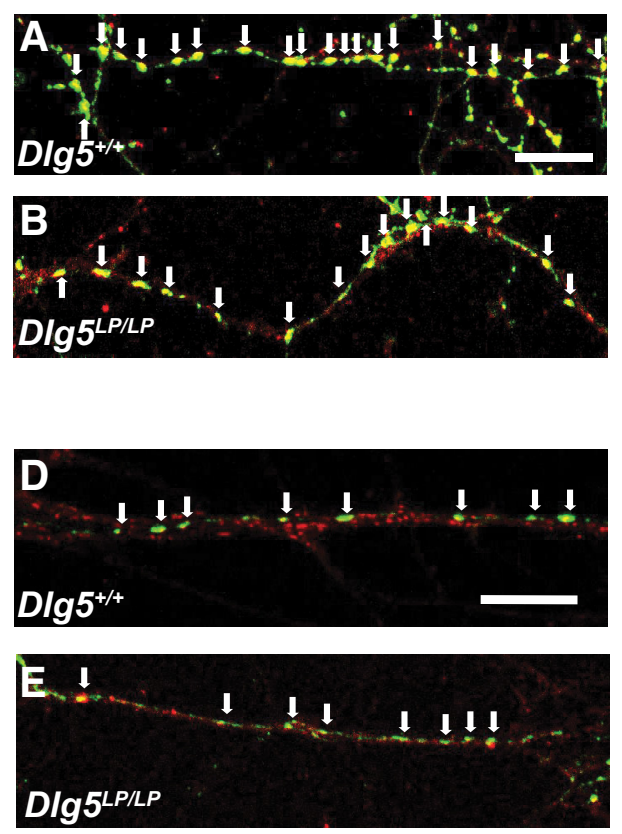

I

$$
D \lg 5^{+/+}
$$
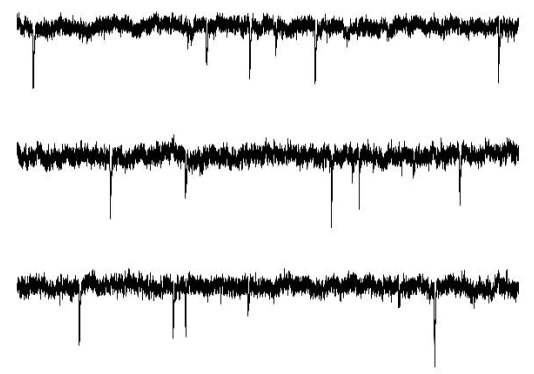

J

$D \lg 5^{L P / L P}$

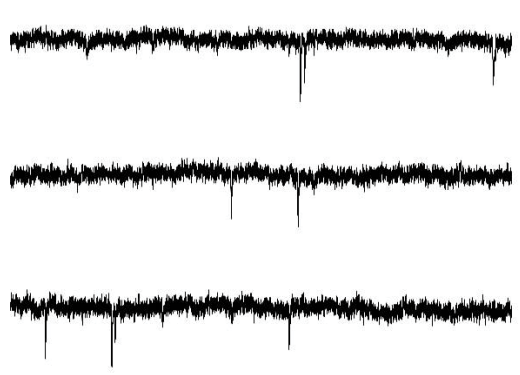

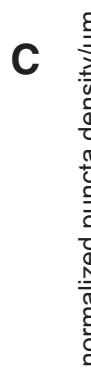

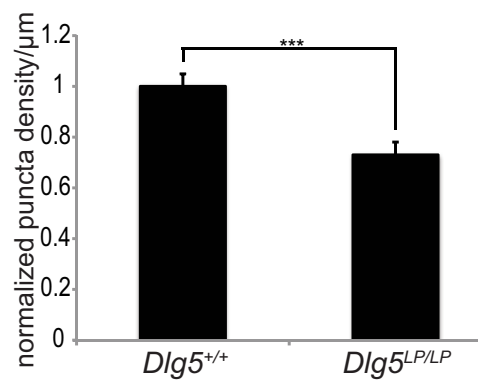

G

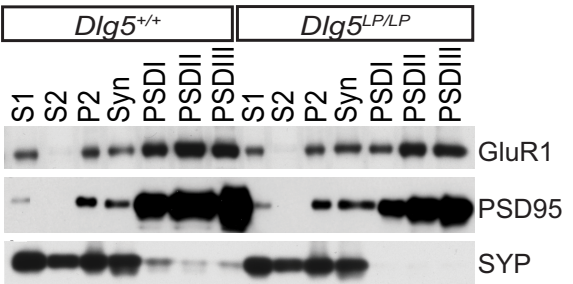

$\mathbf{F}$
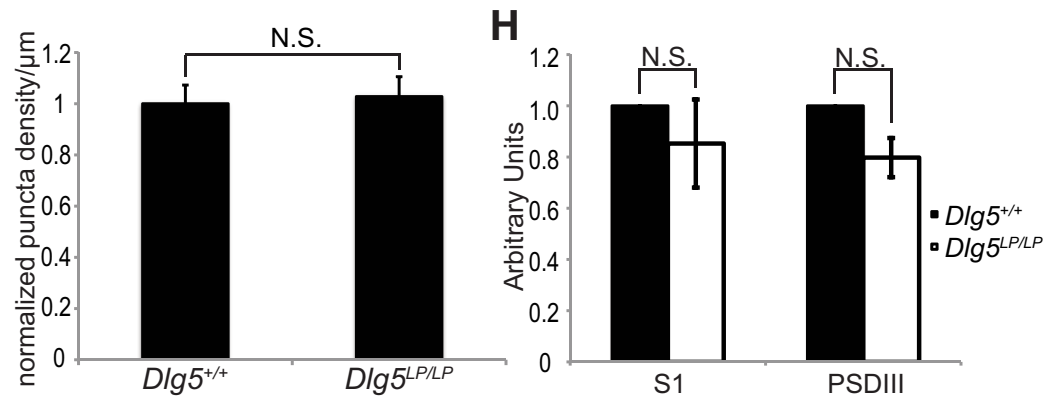

K
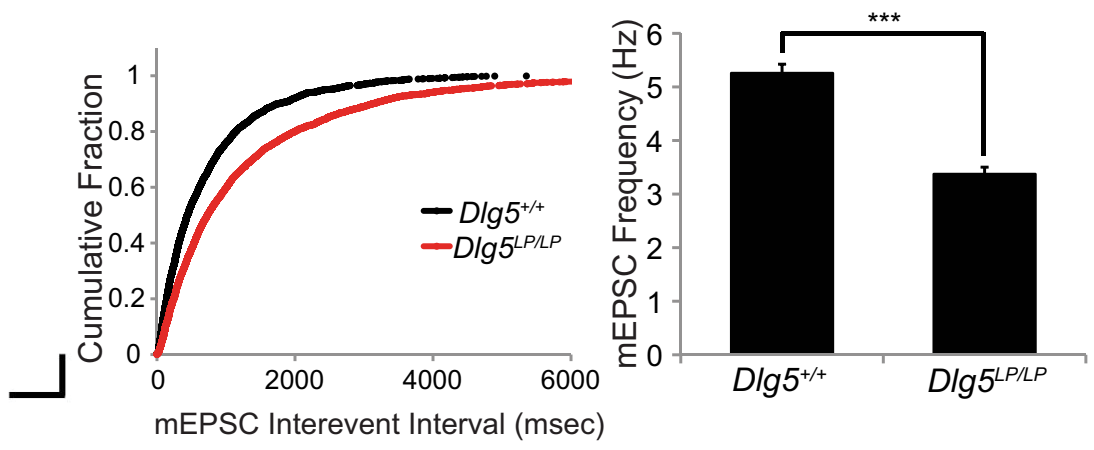

M

N
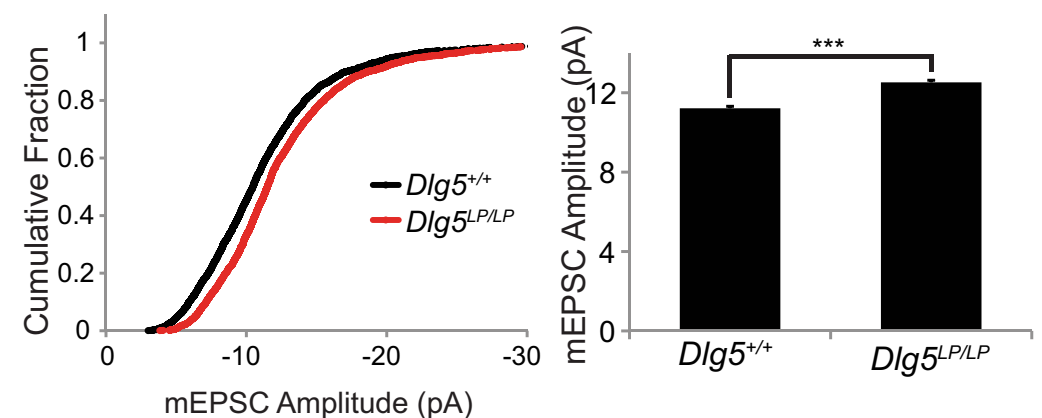

Figure 6. DLG5 regulates excitatory synapse density. $\boldsymbol{A}, \boldsymbol{B}$, Cortical neurons derived from E13.5 Dlg5 ${ }^{+/+}(\boldsymbol{A})$ and Dlg $5^{\mathrm{LP} / \mathrm{LP}}(\boldsymbol{B})$ embryos were cultured for 21 DIV. Excitatory synapses were visualized using antibodies recognizing vGlut1 (green) and PSD95 (red), presynaptic and postsynaptic markers, respectively. Colocalized vGlut1/PSD95 puncta indicate excitatory synapses (white arrows). Dlg $5^{\mathrm{LP} / L \mathrm{P}}$ neurons show significant reduction in excitatory synapse density. Shown are representative images for Dlg $5^{+/+}(\boldsymbol{A})$ and $D / g 5^{\mathrm{LP} / \mathrm{LP}}(\boldsymbol{B})$ dendritic segments. $\boldsymbol{C}, \mathrm{Quantification}$ of excitatory synapses from Dlg $5^{+/+}$and Dlg $5^{\text {LP/LP }}$ cultured neurons. Values are normalized to Dlg $5^{+/+}$neurons:Dlg $5^{+/+}: 1 \pm 0.049 \mathrm{vGlut} 1 /$ PD 95 colocalized puncta/ $\mu$ m; Dlg $5^{\text {LP/LP. }}: 0.729 \pm 0.05$ vGlut1/PSD95 colocalized puncta/ $\mu \mathrm{m}$. Number of neurons quantified: $n=23$ neurons from 3 independent cultures for Dlg $5^{+/+}$, and $n=30$ neurons from 3 independent cultures for Dlg $5^{\mathrm{LP} / \mathrm{LP}}$. Error bars indicate SEM. ${ }^{* * *} p<0.001$ by two-tailed Student's $t$ test. $\boldsymbol{D}, \boldsymbol{E}$, Cortical neurons derived from E13.5 Dlg $5^{+/+}(\boldsymbol{D})$ and Dlg $5^{\mathrm{LP} / \mathrm{LP}}(\boldsymbol{E})$ embryos were cultured for 21 DIV. Inhibitory synapses were visualized using antibodies that recognize VGAT (green) and gephryn (red), presynaptic and postsynaptic inhibitory markers, respectively. Colocalized VGAT/gephryn puncta indicate inhibitory synapses (white arrows). Dlg $5^{\mathrm{LP} / L \mathrm{P}}$ neurons show no reduction in inhibitory synapse density. Representative images for Dlg5 $5^{+/+}(\boldsymbol{D})$ and Dlg5 $5^{\mathrm{LP} / L \mathrm{P}}(\boldsymbol{E})$ dendritic segments are shown. $\boldsymbol{F}$, Quantification of inhibitory synapse density from Dlg $5^{+/+}$and Dlg $5^{\text {LP/LP }}$ cultured cortical neurons. Values are normalized to Dlg $5^{+/+}$neurons: Dlg $5^{+/+}: 1 \pm 0.073$ VGAT/gephryn colocalized puncta/ $\mu \mathrm{m} ; D$ Ig $5^{\text {LP/LP }}: 1.028 \pm 0.077$ VGAT/gephryn colocalized puncta/ $\mu \mathrm{m}$. Number of neurons quantified: $n=18$ neurons from 3 independent cultures for Dlg $5^{+/+}$, and $n=19$ neurons from 3 independent cultures for DIg $5^{\text {LP/LP. }}$ Error bars indicate SEM. N.S. $p=0.794$ by two-tailed Student's $t$ test. G, Western blot analysis of GluR1 in synaptic fractions of (Figure legend continues.) 
electroporation of wild-type E13.5 brains using our Dlg5 shRNA construct and a GFP-expressing control construct. At P21, layer V cortical neurons electroporated with $D l g 5$ shRNA show a $25 \%$ reduction in dendritic spine density compared with neurons electroporated with the GFP control (Fig. 5M-O). In cultured cortical neurons and also in the electroporated brains, only a very small number of neurons receive the Dlg5 shRNA construct, resulting in single, isolated, DLG5-negative neurons surrounded by wild-type neurons and glia. These results demonstrate that DLG5 functions cell autonomously in postsynaptic neurons to regulate dendritic spine development. Given that our shRNA acutely downregulates DLG5 protein expression, these results further suggest that the reduction in dendritic spine density observed in Dlg5 ${ }^{\mathrm{LP} / \mathrm{LP}}$ mutants is due to a lack of neuronal DLG5 function and does not result from progressive enlargement of lateral ventricles.

\section{Dlg5 mutants exhibit decreased excitatory synapse density and altered synaptic properties}

Dendritic spines are sites of excitatory synaptic contact (Nimchinsky et al., 2002). To investigate whether there is a corresponding change in excitatory synapse number in $\mathrm{Dlg} 5^{\mathrm{LP} / \mathrm{LP}}$ mice, we first analyzed synapse density in cultured cortical neurons by immunostaining with synaptic markers. Cortical neurons from E13.5 embryos were cultured for 21 DIV and then stained for the excitatory presynaptic marker vGlut and the postsynaptic marker PSD95. Colocalization of vGlut1 and PSD95 puncta was then determined to assess excitatory synapse number. Consistent with our dendritic spine analysis, we observed a $27 \%$ decrease in vGlut1/PSD95 double-positive puncta in dendrites of cultured $D \lg 5^{\mathrm{LP} / \mathrm{LP}}$ neurons (Fig. $6 A-C$ ). In addition, we stained cultured cortical neurons for the inhibitory presynaptic marker VGAT and the postsynaptic marker gephyrin. We observed no change in VGAT/gephyrin double-positive puncta in cultured $D \lg 5^{\mathrm{LP} / \mathrm{LP}}$ cortical neurons (Fig. $6 D-F$ ), suggesting that DLG5 does not affect inhibitory synaptogenesis.

Glutamate receptors are the predominant excitatory neurotransmitter receptor in the mammalian brain and MAGUK proteins, including PSD95, regulate AMPA receptor localization and trafficking (Kim and Sheng, 2004). To investigate whether DLG5 has a similar role in regulating synaptic localization of AMPA receptors, we performed Western blot analysis of GluR1 in subcellular fractions prepared from P21 $\mathrm{Dlg} 5^{+/+}$and

\section{$\leftarrow$}

(Figure legend continued.) Dlg $5^{+/+}$and Dlg $5^{\mathrm{LP} / \mathrm{LP}}$ brains. Subcellular fractionation of P21 mouse forebrains was performed to generate fractions progressively enriched in synaptic membranes, as verified by immunoblotting for PSD-95 and synaptophysin. There is no significant difference in the level and distribution of GluR1. $\boldsymbol{H}$, Quantification of GluR1 protein levels from S1 and PSD fractions prepared from Dlg $5^{+/+}$and Dlg $5^{\text {LP/P }}$ littermates, normalized to Dlg $5^{+/+}$protein levels (Dlg5 $5^{\text {LP/LP }}$ S1: $0.85 \pm 0.172$, PSDIII: $\left.0.80 \pm 0.076\right) . n=3$ brains for $D l g 5^{+/+}$and $n=3$ brains for Dlg $5^{\text {LP/LP }}$. Error bars indicate SEM. N.S. $p=0.482$ (S1) and $p=$ 0.118 (PSDIII) by two-tailed Student's $t$ test. $I, J$, Layer V cortical neuron mEPSCs were recorded from $D l g 5^{+/+}$and $D \lg 5^{\text {LP/LP }}$ somatosensory cortical slices. Sample traces from $D \lg 5^{+/+}(\mathbf{G})$ and $\operatorname{Dlg} 5^{\mathrm{LP} / \mathrm{LP}}(\boldsymbol{H})$ are shown. $\boldsymbol{K}$, The cumulative plot shows an increase in mEPSC interevent interval in Dlg $5^{\text {LP/LP }}$ layer V cortical neurons. Statistically significant by Kolmogorov-Smirnoff test. $L$, $\mathrm{mEPSC}$ frequency is reduced in Dlg $5^{\mathrm{LP} / \mathrm{LP}}$ layer V cortical neurons $\left(D \lg 5^{+/+}: 5.254 \pm\right.$ $0.17 \mathrm{~Hz}$; Dlg5 ${ }^{\text {LP/LP }}: 3.37 \pm 0.132 \mathrm{~Hz}$.). Number of neurons recorded: $n=25$ neurons from 8 mice for $D l g 5^{+/+}$, and $n=25$ neurons from 6 mice for $D \lg 5^{\text {LP/LP }}$. Error bars indicate SEM. ${ }^{* * *} p<0.001$ by two-tailed Student's $t$ test. $\boldsymbol{M}$, The cumulative plot shows a modest but significant increase in $\mathrm{mEPSC}$ amplitude in Dlg $5^{\mathrm{LP} / \mathrm{LP}}$ layer V cortical neurons. Statistically significant by Kolmogorov-Smirnoff test. $N$, mEPSC amplitude is modestly increased in Dlg5 $5^{\text {LP/LP }}$ layer V cortical neurons $\left(D \lg 5^{+/+}: 11.216 \pm 0.01 \mathrm{pA}\right.$; Dlg $\left.5^{\text {LP/LP }}: 12.523 \pm 0.106 \mathrm{pA}\right)$. Error bars indicate SEM. ${ }^{* * *} p<0.001$ by two-tailed Student's $t$ test. Scale bars: $10 \mu \mathrm{m}$ for $\boldsymbol{A}$ and $\boldsymbol{B}$, $10 \mu \mathrm{m}$ for $\boldsymbol{D}$ and $\boldsymbol{E}$.
$D \lg 5^{\text {LP/LP }}$ forebrain lysates. We observe no significant difference in the amount or distribution of GluR1 in postsynaptic density fractions (Fig. 6G,H). These results suggest that DLG5 regulates excitatory synapse density without affecting synaptic glutamate receptor levels.

To investigate the functional consequences of decreased excitatory synapse density in $\mathrm{Dlg} 5^{\mathrm{LP} / \mathrm{LP}}$ mutants, we performed wholecell patch-clamp recordings of layer $\mathrm{V}$ cortical neurons in cortical slices derived from P21-P28 mice. mEPSC analysis revealed a $36 \%$ reduction in mEPSC frequency in $D \lg 55^{\mathrm{LP} / \mathrm{LP}}$ neurons (Fig. $6 I-L)$. The altered cortical morphology that results from the enlarged cortical ventricles at $\mathrm{P} 21$ in $D \lg 5^{\mathrm{LP} / \mathrm{LP}}$ mutant brains precluded performing paired-pulse recordings from layer $\mathrm{V}$ cortical neurons. Nevertheless, we show that DLG5 functions cell autonomously in postsynaptic neurons to regulate dendritic spine density (Fig. 5) and Dlg $5^{\mathrm{LP} / \mathrm{LP}}$ neurons have normal presynaptic terminal morphology as assessed by TEM analysis (see next paragraph). Therefore, the reduction in mEPSC frequency in Dlg5 ${ }^{\mathrm{LP} / \mathrm{LP}}$ neurons most likely results from decreased numbers of excitatory synapses rather than a decrease in presynaptic release probability. There was a slight increase of $\sim 10 \%$ in mEPSC amplitude in $D \lg 5^{\mathrm{LP} / \mathrm{LP}}$ neurons (Fig. $6 \mathrm{M}, N$ ). We did not observe a significant difference in the levels of synaptic AMPA receptors in Dlg5 ${ }^{\mathrm{LP} / \mathrm{LP}}$ brains (Fig. $6 G, H$ ); therefore, this modest increase in mEPSC amplitude could be due to other compensatory mechanisms or as yet unidentified molecular interactions involving DLG5 that affect glutamate receptor function. These results reveal a significant reduction in excitatory synaptic transmission onto layer $\mathrm{V}$ cortical neurons in $D \lg 5^{\mathrm{LP} / \mathrm{LP}}$ mice, consistent with our observation of a reduction in the number of excitatory synapses in these mutants.

To investigate the effects of the $D \lg 5^{\mathrm{LP}}$ mutation on spine morphology and synapse formation in vivo, we used TEM to analyze $D \lg 5^{\mathrm{LP} / \mathrm{LP}}$ cortical neurons at high resolution. In agreement with our in vitro observations, we found a $25 \%$ decrease in synapse density in layer $\mathrm{V} \mathrm{Dlg} 5^{\mathrm{LP} / \mathrm{LP}}$ cortical neurons (Fig. $7 A, B, E)$; however, excitatory synapse morphology was apparently normal (Fig. 7C,D). Quantification of spine area, PSD length, synaptic vesicle number per terminal, and synaptic vesicle diameter (Fig. $7 F-I$ ) shows that synapses in the $D \lg 5^{\mathrm{LP} / \mathrm{LP}}$ cortex are indistinguishable from those observed in wild-type. These results suggest that DLG5 is involved primarily in initial synapse formation, but not subsequent synaptic maturation or remodeling.

\section{The DLG5 ${ }^{\mathrm{L} 1642 \mathrm{P}} \mathrm{SH} 3$ domain mutation disrupts interactions between the DLG5 SH3 and GUK domains}

Although DLG5 protein levels in the Dlg5 $5^{\mathrm{LP} / \mathrm{LP}}$ mutant brain are reduced by $\sim 50 \%$, the reduction in $D \lg 5^{\mathrm{LP} / \mathrm{LP}}$ dendritic spine density is comparable to that observed in Dlg $5^{\text {null/null }}$ mice (Fig. $4 J-L$ ), suggesting that the $L 1642 P$ mutation affects the normal function of DLG5. The L1642P point mutation lies within the DLG5 SH3 domain, a domain also present in other MAGUK proteins including PSD95 (Kim and Sheng, 2004). The PSD95 $\mathrm{SH} 3$ domain structure differs greatly from canonical SH3 domains, lacking the characteristic secondary structure required for interactions with proline-rich motifs (McGee et al., 2001). Instead, the PSD95 SH3 domain binds to its own GUK domain in an intramolecular fashion and this interaction may be important for the regulated assembly of PSD95 oligomers or the formation of protein conformations essential for interactions with other cell surface proteins and signaling molecules (McGee and Bredt, 1999; McGee et al., 2001; Tavares et al., 2001). In the crystal 

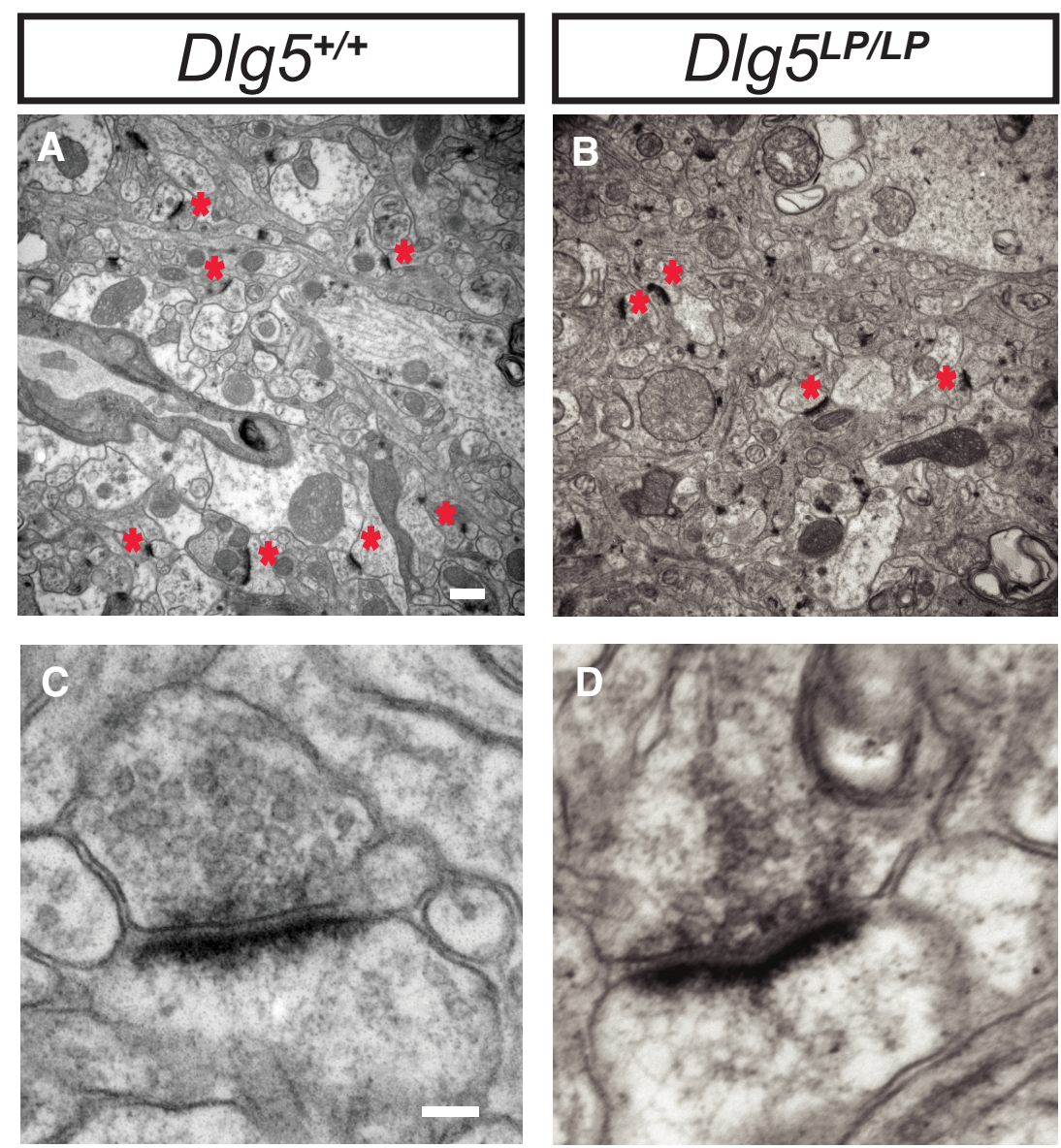

E

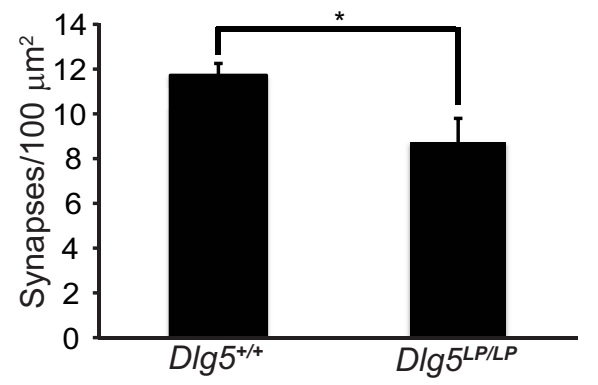

\section{F}

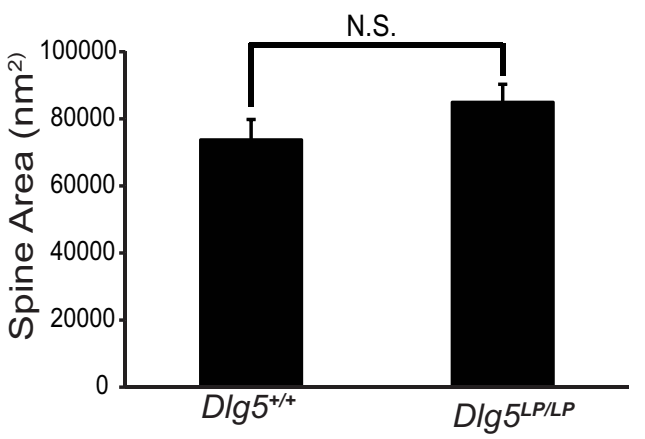

G

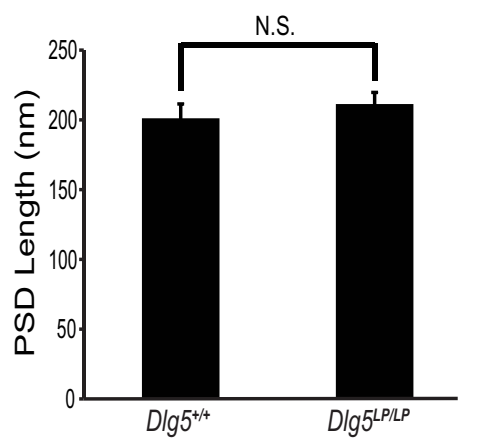

H

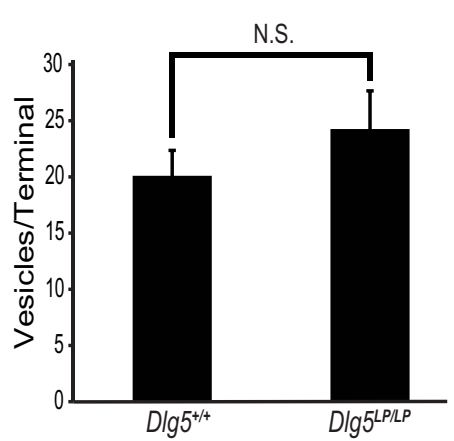

I

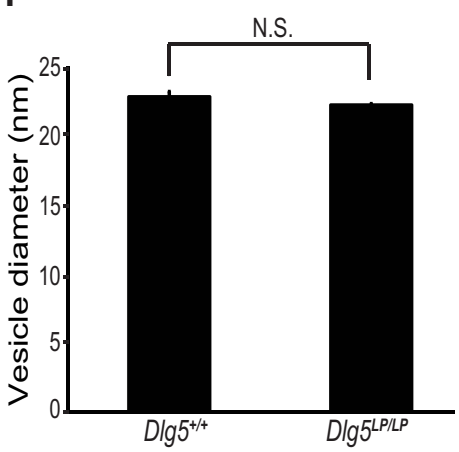

Figure 7. Ultrastructural analysis shows decreased excitatory synapse density but normal synapse morphology in Dlg $5^{\mathrm{LP} / \mathrm{LP}}$ mice. $\boldsymbol{A}, \boldsymbol{B}, \mathrm{TEM}$ analysis of layer V cerebral cortex at P21 reveals a significant reduction in excitatory synapse density in $D l g 5^{\text {LP/LP }}$ brains $(\boldsymbol{A})$ compared with $D / g 5^{+/+}$brains $(\boldsymbol{B})$. Red asterisks represent excitatory synapses. $\boldsymbol{C}, \boldsymbol{D}$, Higher-magnification TEM views of of $D / g 5^{+/+}(C)$ and $D l g 5^{\text {LP/LP }}(\mathbf{D})$ cortical neuron dendritic spines. Synapse morphology appears normal in Dlg5 ${ }^{\text {LP/LP }}$ mice. E, Quantification of excitatory synapse (Figure legend continues.) 
structure of the related MAGUK protein human Z0-1 (Nomme et al., 2011), isoleucine562 in the SH3 domain, which is homologous to leucine1642 in DLG5, is positioned $\sim 4.3$ A from tryptophan799 in the GUK domain and these two residues make contact within the hydrophobic core (Fig. 8A). The close proximity of this amino acid pair suggests that leucine1642 in the DLG5 SH3 domain may be important for interactions between the DLG5 SH3 and GUK domains. Conformational rigidity of the proline that replaces the leucine in the DLG5 ${ }^{\mathrm{LP}}$ mutant could destabilize this interaction. Given the position of leucine1642 at the binding interface between the SH3 and GUK domains, we investigated whether the DLG5 SH3 domain binds to the DLG5 GUK domain and if the L1642P mutation disrupts this interaction. We cotransfected HEK293T cells with a construct expressing FLAG-tagged DLG5 WT or L1642P SH3 domains and a construct expressing MYC-tagged DLG GUK. Immunoprecipitation of cell lysates from these HEK293T cells with anti-Myc and detection of FLAG-tagged SH3 in the anti-Myc immunoprecipitates show that the DLG5 SH3 domain indeed binds to the DLG5 GUK domain (Fig. 8B). Importantly, the binding of the DLG5 ${ }^{\mathrm{L} 1642 \mathrm{P}} \mathrm{SH} 3$ domain to the DLG5 GUK domain is greatly reduced. Quantification of coimmunoprecipitated $\mathrm{SH} 3$ domain normalized to input levels shows an $\sim 75 \%$ reduction in the amount of coimmunoprecipitated L1642P SH3 domain (Fig. $8 C$ ), indicating that the L1642P mutation disrupts protein-protein interactions between DLG5 SH3 and GUK domains.

\section{Neuronal subcellular localization of $\boldsymbol{\beta}$-catenin and cell surface localization of $N$-cadherin are compromised in Dlg5 ${ }^{\mathrm{LP} / \mathrm{LP}}$ mice}

How might disruption of DLG5 protein domain interactions affect dendritic spine formation and synaptogenesis? Previous work shows that DLG5 binds to $\beta$-catenin and is required for the delivery of catenin-cadherin complexes to the plasma membrane of epithelial cells and for their stabilization (Nechiporuk et al., 2007). Catenin-cadherin protein complexes are essential components of adherens junctions and synapses (Arikkath and Reichardt, 2008). $\beta$-Catenin is driven into dendritic spines upon depolarization (Murase et al., 2002) and is required for regulating synaptic strength and spine morphology in hippocampal neurons in vitro (Okuda et al., 2007). $N$-cadherin regulates dendritic spine density (Saglietti et al., 2007), morphology (Togashi et al., 2002), and stabilization after LTP in vitro in hippocampal slice cultures (Bozdagi et al., 2010; Mendez et al., 2010). The molecular

\footnotetext{
$\leftarrow$

(Figure legend continued.) density by TEM (Dlg $5^{+/+}: 11.719 \pm 0.534$ synapses $/ \mu \mathrm{m}^{2} ;$ Dlg $5^{\text {LP/ }}$ LP: $8.75 \pm 1.048$ synapses $/ \mu \mathrm{m}^{2}$ ). Number of synapses quantified: $n=75$ from 3 brains for $D \operatorname{Dlg} 5^{+/+}$and $n=56$ from 3 brains for Dlg $5^{\text {LP/LP. }}$. Error bar represents SEM. ${ }^{*} p<0.05$ by two-tailed Student's $t$ test. $F$, Quantification of mean dendritic spine area by TEM $\left(D \lg 5^{+/+}\right.$: $73699.39 \pm 891.08 \mathrm{~nm}^{2} ;$ Dlg $5^{\text {LP/LP }}: 84903.79 \pm 685.4 .25 \mathrm{~nm}^{2}$ ). Number of spines quantified: $n=47$ from 3 brains for Dlg $5^{+/+}$, and $n=62$ from 3 brains for Dlg $5^{\text {LP/LP }}$. Error bar represents SEM. N.S. $p=0.17$ by two-tailed Student's t test. G, Quantification of mean PSD length by TEM $\left(D l g 5^{+/+}: 201.14 \pm 10.27 \mathrm{~nm} ; D \operatorname{Dlg} 5^{\text {LP/LP: }}: 211.35 \pm 8.34 \mathrm{~nm}\right)$. Number of synapses quantified: $n=42$ from 3 brains for Dlg $5^{+/+}$, and $n=67$ from 3 brains for Dlg $5^{\text {LPLP. }}$. Error bar represents SEM. N.S. $p=0.7$ by two-tailed Student's $\boldsymbol{t}$ test. $\boldsymbol{H}$, Quantification of mean number of presynaptic vesicles by TEM (Dlg $\left.5^{+/+}: 20.1 \pm 2.26 ; D \operatorname{Dg} 5^{\text {LP/LP }}: 24.26 \pm 3.4\right)$. Number of synapses quantified: $n=30$ from 3 brains for $D l g 5^{+/+}$, and $n=34$ from 3 brains for $D / g 5^{\text {LP/LP }}$. Error bar represents SEM. N.S. $p=0.36$ by two-tailed Student's $t$ test. $I$, Quantification of synaptic vesicle diameter by TEM $\left(D / g 5^{+/+}: 22.75 \pm 0.382 \mu \mathrm{m}\right.$; Dlg $5^{\text {LP/LP: }}: 22.16 \pm 0.316$ $\mu \mathrm{m})$. Number of vesicles quantified: $n=108$ vesicles from 26 synapses from 3 brains for $D \lg 5^{+/+}$, and $n=134$ vesicles from 35 synapses from 3 brains for Dlg $5^{\text {LP/LP }}$. Scale bars: 500 $\mathrm{nm}$ for $\boldsymbol{A}$ and $\boldsymbol{B}, 50 \mathrm{~nm}$ for $\boldsymbol{C}$ and $\boldsymbol{D}$.
}

mechanisms that regulate catenin-cadherin protein localization in neurons, however, are poorly understood.

To investigate whether DLG5 binds to $\beta$-catenin in the early postnatal brain, lysates from P12 Dlg $5^{+/+}$and $D \lg 5^{\mathrm{LP} / \mathrm{LP}}$ mouse brains were coimmunoprecipitated with anti- $\beta$-catenin antibody and immunoblotted for DLG5. We found that similar levels of DLG5 were coimmunoprecipitated with $\beta$-catenin in $D \lg 5^{+/+}$ and $D \lg 5^{\mathrm{LP} / \mathrm{LP}}$ brain lysates (Fig. $8 D, E$ ), showing that DLG5 interacts with $\beta$-catenin during early postnatal neural development and that this interaction is not directly affected by the L1642P mutation. We next examined the effect of the $D \lg 5^{\mathrm{LP}}$ mutation on $\beta$-catenin, $N$-cadherin, and PSD95 protein levels and subcellular localization in cortical neurons. We performed Western blot analysis of forebrain lysates derived from P21 Dlg5 ${ }^{+/+}$and $D \lg 5^{\mathrm{LP} / \mathrm{LP}}$ mice and observed no significant difference in $\beta$-catenin, $N$-cadherin, or PSD95 total protein levels (Fig. $8 F, G$ ). Therefore, the effect of DLG5 on excitatory synaptogenesis and synaptic transmission is likely not due to an alteration of $\beta$-catenin or $N$-cadherin total protein levels or to a secondary effect on protein levels of other MAGUK proteins such as PSD95.

To address the effect of the Dlg5 mutation on neuronal $\beta$-catenin localization, we cultured cortical neurons from E13.5 $D \lg 5^{+/+}$and $D \lg 5^{\mathrm{LP} / \mathrm{LP}}$ mice for $21 \mathrm{DIV}$ and then immunostained for $\beta$-catenin and vGlut 1 . $\beta$-catenin and vGlut 1 double-positive puncta indicate synaptic $\beta$-catenin, and we observed punctate distribution of $\beta$-catenin along the dendrites of both $D \lg 5^{+/+}$ and $D \lg 5^{\mathrm{LP} / \mathrm{LP}}$ neurons; however, we found an $\sim 30 \%$ reduction in the number of $\beta$-catenin/vGlutl double-positive puncta in $D \lg 5^{\mathrm{LP} / \mathrm{LP}}$ dendrites (Fig. $8 \mathrm{H}, \mathrm{I}$ ). Therefore, loss of DLG5 affects the targeting or stabilization of $\beta$-catenin in synpases of cortical neurons. These results strongly suggest that mislocalization of $\beta$-catenin contributes to the dendritic spine and synaptogenesis defects that we observed in $D \lg 5^{\mathrm{LP} / \mathrm{LP}}$ neurons.

Because the $D \lg 5^{\mathrm{LP} / \mathrm{LP}}$ mutation affects $\beta$-catenin localization to synapses, this interaction could serve to direct the surface localization of $\mathrm{N}$-cadherin in cortical neurons. We used a surface biotinylation assay to assess $N$-cadherin cell surface levels in cultured cortical neurons. Although the total amount of $N$-cadherin protein remains unchanged in $D \lg 5^{\mathrm{LP} / \mathrm{LP}}$ neurons compared with wild-type neurons, we observed a dramatic decrease in cell surface levels of $N$-cadherin (Fig. $8 J$ ). Quantification of surface $\mathrm{N}$-cadherin levels normalized to total $\mathrm{N}$-cadherin revealed an $\sim 80 \%$ decrease in the fraction of $N$-cadherin targeted to the cell surface in Dlg5 ${ }^{\mathrm{LP} / \mathrm{LP}}$ neurons (Fig. $8 K$ ). Therefore, the DLG5 ${ }^{\text {L1642P }}$ mutation markedly disrupts synaptic localization of $\beta$-catenin and leads to greatly decreased $N$-cadherin levels at the cortical neuronal surface.

\section{DLG5 and $N$-cadherin interact functionally in vitro and in vivo}

We found that DLG5 is required for dendritic spine formation and cell surface localization of $\mathrm{N}$-cadherin. Previous studies on the role of $\mathrm{N}$-cadherin in spine development and synaptic function were performed in vitro using hippocampal neurons (Togashi et al., 2002; Saglietti et al., 2007; Bozdagi et al., 2010; Mendez et al., 2010). In contrast, little is known about how $\mathrm{N}$-cadherin affects these developmental processes in cortical neurons. To address this issue, we used a previously characterized shRNA (Saglietti et al., 2007) to knockdown N-cadherin in cortical neurons in vitro. Cultured cortical neurons were transfected with $N$-cadherin shRNA at DIV 8 and cultured for a total of 21 DIV. We observed a $45 \%$ decrease in dendritic spine density after $N$-cadherin knockdown (Fig. $9 A-D$ ), demonstrating that 

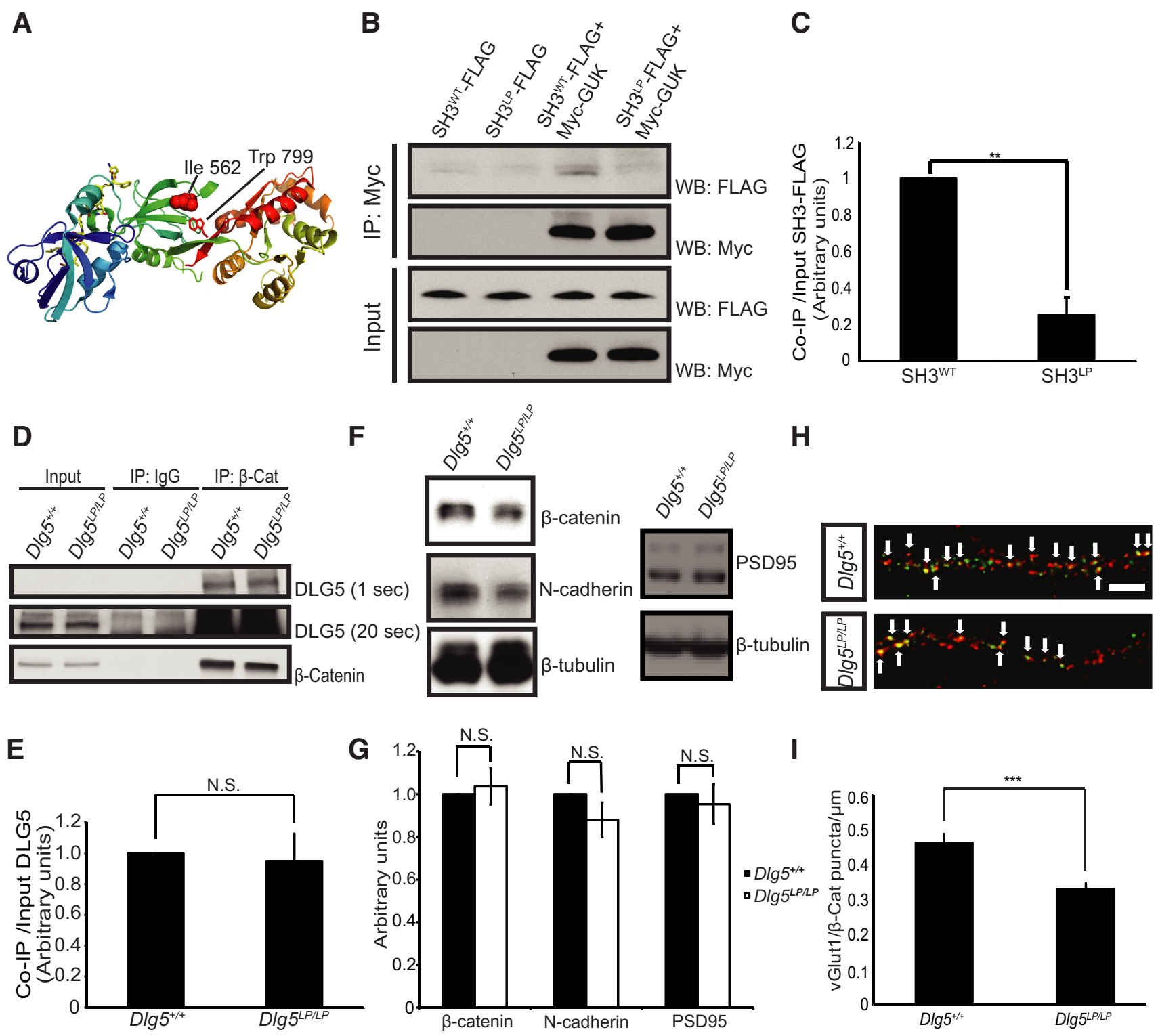

$\mathbf{J}$

K
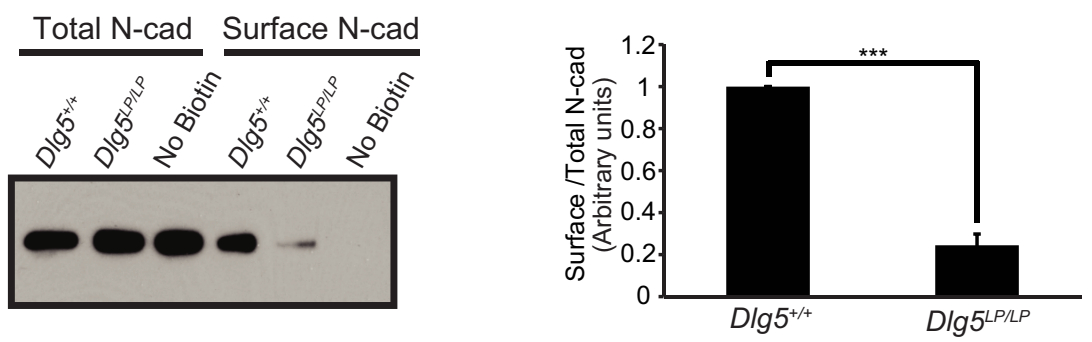

Figure 8. DLG5 regulates neuronal $\beta$-catenin and N-cadherin localization. $A$, Crystal structure of human Z0-1 SH3-GUK domain presented as ribbon diagram (Nomme et al., 2011). Isoleucine 562 homologous to DLG5 leucine 1642 and tryptophan 799 are highlighted. B. HEK 293 T cells were transfected with FLAG-tagged wild-type SH3 alone, FLAG-tagged SH3 ${ }^{\text {L1642P }}$ alone, FLAG-tagged wild-type SH3 with Myc-tagged GUK, or FLAG-tagged SH3 ${ }^{\text {L1642P }}$ with Myc-tagged GUK. Cell lysates were immunoprecipitated with Myc antibody and immunoblotted for FLAG and Myc. The amount of $\mathrm{SH}_{3}{ }^{\mathrm{L} 1642 \mathrm{P}}$ that coimmunoprecipitated with GUK was significantly reduced compared with that of wild-type SH3. The input is $1 \%$ of the lysate used for immunoprecipitation.C, Quantification shows decreased coimmunoprecipitated SH3 ${ }^{\mathrm{L} 1642 \mathrm{P}}$ normalized to input levels ( $\mathrm{SH} 3^{\mathrm{LP}}: 0.25 \pm 0.095$ ). The amount of coimmunoprecipitated $\mathrm{SH} 3^{\mathrm{WT}}$ normalized to input levels is designated as 1 . Error bar represents SEM. $n=4$ independent experiments. ${ }^{* *} p<0.01$ by two-tailed Student's $t$ test. D, Brain lysates from P12 Dlg $5^{+/+}$and Dlg $5^{\text {LPLP }}$ mice were immunoprecipitated with $\beta$-catenin antibody and immunoblotted for $\beta$-catenin and DLG5. The input is $5 \%$ of the lysate used for immunoprecipitation. $E$, Quantification shows similar amount of coimmunoprecipitated DLG5 normalized to input levels in Dlg $5^{+/+}$and Dlg $5^{\text {LPLP }}$ brain lysate (Dlg $5^{\text {LP/P. }}: 0.95 \pm 0.178$ ). The amount of coimmunoprecipitated DLG5 normalized to input levels in Dlg $5^{+/+}$is designated as 1. Error bar represents SEM. $n=3$ brains for DIg $5^{+/+}$and $n=5$ brains for Dlg $5^{\text {LP } / \text { LP }}$. N.S. $p=0.801$ by two-tailed Student's $t$ test. $F$, Western-blot analysis of $\beta$-catenin, $N$-cadherin, and PSD 95 protein levels in total brain lysates prepared from P21 $\mathrm{Dlg} 5^{+/+}$and $\mathrm{Dlg} 5^{\mathrm{LP} / \mathrm{LP}}$ littermates. There is no significant difference in $\beta$-catenin, $N$-cadherin, and PSD95 protein levels. $G, Q$ uantification of $\beta$-catenin, $N$-cadherin, and PSD95 protein levels from total brain lysates prepared from $D \lg 5^{+/+}$and Dlg $5^{\mathrm{LP} / \mathrm{LP}}$ littermates, normalized to Dlg5 $5^{+/+}$protein levels (Figure legend continues.) 
$\mathrm{N}$-cadherin is also required for spine formation in cortical neurons.

If this decrease in spine density in $D \lg 5{ }^{\mathrm{LP} / \mathrm{LP}}$ neurons is indeed caused by reduction of cell surface $\mathrm{N}$-cadherin, then this phenotype should be suppressed by $\mathrm{N}$-cadherin gain of function. Cortical neurons cultured from E13.5 Dlg $5^{+/+}$and $D \lg 5^{\mathrm{LP} / \mathrm{LP}}$ mice were transfected with a construct expressing GFP-tagged $\mathrm{N}$-cadherin at $8 \mathrm{DIV}$ and then cultured for a total of $21 \mathrm{DIV}$. Although overexpression of $\mathrm{N}$-cadherin had no effect on spine density in $\mathrm{Dlg} 5^{+/+}$neurons, it restored spine density in $\mathrm{Dgl5} \mathrm{LP}^{\mathrm{LP} / \mathrm{LP}}$ neurons to wild-type levels (Fig. $9 E-H$ ). These results demonstrate that the reduction in spine density in $\mathrm{Dlg} 5^{\mathrm{LP} / \mathrm{LP}}$ neurons can be ameliorated by $\mathrm{N}$-cadherin gain-of-function through overexpression.

Finally, we investigated whether $D l g 5$ and $\mathrm{N}$-cadherin genetically interact in vivo by performing transheterozygous genetic analysis. To obtain $\mathrm{N}-\mathrm{cad}^{+1-}$ mice, we first bred $\mathrm{N}$-cad dlox/flox $^{\text {flox }}$ mice (Kostetskii et al., 2005) to Sox2-Cre mice, inducing germline deletion of $\mathrm{N}$-cad. $\mathrm{N}$ - $\mathrm{cad}^{+/-}$mice were bred to $\mathrm{Dlg} 5^{\mathrm{LP} /+}$ mice to obtain $\mathrm{Dlg} 5^{\mathrm{LP} /+} ; \mathrm{N}-\mathrm{cad}^{+/-}$mice. Layer V cortical pyramidal neurons in P21 mice were then examined using Golgi labeling. Although dendritic spine density of $\mathrm{Dlg} 5^{\mathrm{LP} /+}$ or $\mathrm{N}-\mathrm{cad}^{+/-}$cortical pyramidal neurons did not differ from wild-type, there was an $\sim 20 \%$ reduction in spine density in $\mathrm{Dlg}^{\mathrm{LP} /+} ; \mathrm{N}-\mathrm{cad}^{+/-}$ trans-heterozygous neurons (Fig. 9I-M). Together, these results strongly suggest that a decrease in cell-surface $\mathrm{N}$-cadherin is the underlying cause of the spine density reduction observed in $D \lg 5^{\mathrm{LP} / \mathrm{LP}}$ neurons.

\section{Discussion}

DLG5 regulates dendritic spine development

We show here that the DLG5 MAGUK protein is an important regulator of dendritic spine and excitatory synapse density and function in cortical pyramidal neurons. Loss of DLG5 leads to a decrease in the number of dendritic spines, loss of excitatory synapses, and impaired excitatory transmission. At the molecular level, DLG5 is required for the proper localization of $N$-cadherin to the cell surface of cortical neurons. These findings describe a unique mechanism by which a MAGUK protein affects dendritic spine formation and synaptogenesis: regulating the subcellular localization of a trans-synaptic cell adhesion molecule.

The DLG family of MAGUK proteins includes intracellular scaffolding components composed of multiple protein interac-

\section{$\leftarrow$}

(Figure legend continued.) (Dlg5 $5^{\text {L/LP }} \beta$-catenin: $1.04 \pm 0.084, N$-cadherin: $0.88 \pm 0.081$, PSD95: $0.95 \pm 0.092) . n=5$ brains for Dlg $5^{+/+}$and $n=5$ brains for Dlg $5^{\text {LP/LP }}$. Error bars indicate SEM. N.S. $p=0.690$ ( $\beta$-catenin), $p=0.171$ ( $N$-cadherin), and $p$ - 0.635 by two-tailed Student's $t$ test. $\boldsymbol{H}$, Cortical neurons derived from E13.5 Dlg $5^{+/+}$and Dlg $5^{\text {LP/LP }}$ embryos were cultured for 21 DIV and stained for $\beta$-catenin and vGlut1. Dlg $5^{\text {LP/LP }}$ neurons show a decrease in dendritic vGlut $1 / \beta$-catenin double-positive puncta (white arrows) density. I, Quantification of $\mathrm{vGlut} 1 / \beta$-catenin double-positive puncta density in dendrites of cortical neurons cultured for 21 DIV (Dlg $5^{+/+}: 0.46 \pm 0.026$ puncta $/ \mu \mathrm{m} ; D$ lg $\left.5^{\text {LP/LP }}: 0.33 \pm 0.016 \mathrm{puncta} / \mu \mathrm{m}\right)$. Number of neurons quantified: $n=27$ from 3 independent cultures for $D l g 5^{+/+}$, and $n=27$ from 3 independent cultures for Dlg $5^{\text {LP/LP }}$. Error bar represents SEM. ${ }^{* * *} p<0.001$ by two-tailed Student's $t$ test. J, Cortical neurons from E13.5 Dlg $5^{+/+}$and Dlg $5^{\text {LP/LP }}$ embryos were cultured for 21 DIV. Surface proteins were biotinylated and precipitated using streptavidin beads. The precipitate and the input ( $5 \%$ of the lysate used for immunoprecipitation), was immunoblotted for $\mathrm{N}$-cadherin to reveal surface $\mathrm{N}$-cadherin and total $\mathrm{N}$-cadherin, respectively. Surface $\mathrm{N}$-cadherin was decreased in Dlg $5^{\mathrm{LP} / \mathrm{LP}}$ neurons, whereas total $\mathrm{N}$-cadherin remains the same. $\boldsymbol{K}$, Quantification of surface $\mathrm{N}$-cadherin levels normalized to total $\mathrm{N}$-cadherin levels (Dlg $5^{\mathrm{LP} / \mathrm{LP} \text { : }}$ $0.24 \pm 0.053$ ). Cell surface $N$-cadherin normalized to total $N$-cadherin in $D l g 5^{+/+}$neurons is designated as 1. Error bar represents SEM. $n=5$ independent cultures for $D l g 5^{+/+}$, and 5 independent cultures for $\mathrm{Dlg} 5^{\mathrm{LP} / \mathrm{LP}} .{ }^{* * *} p<0.001$ by two-tailed Student's $t$ test. Scale bar in $\mathbf{D}$, $10 \mu \mathrm{m}$. tion domains that facilitate the assembly of large molecular complexes at synapses. One of the best-studied DLG family members, PSD95, controls the localization and trafficking of glutamate receptors through direct interactions with NMDA receptors and also indirect interactions with AMPA receptors that are mediated by transmembrane AMPA receptor regulatory proteins (TARPs; Kim and Sheng, 2004). PSD95 also interacts with a myriad of signaling proteins to regulate synaptic properties and plasticity (Kim and Sheng, 2004; Feng and Zhang, 2009). Consistent with a role in regulating glutamate receptor trafficking and synaptic plasticity, PSD95 mutant mice show facilitated LTP induction, impaired LTD, and impaired spatial learning (Migaud et al., 1998; Elias et al., 2006; Cuthbert et al., 2007; Carlisle et al., 2008). In contrast, the role of PSD95 in regulating dendritic spine and synapse densities in vivo remains enigmatic (Migaud et al., 1998; El-Husseini et al., 2000; Béique et al., 2006; Vickers et al., 2006). A previous study on PSD95 mutant mice revealed an increase in spine density localized to specific dendritic segments of hippocampal neurons (Vickers et al., 2006). However, this is in contrast to earlier work showing an increase in spine density in cultured hippocampal neurons that overexpress PSD95 (ElHusseini et al., 2000). It is also not clear whether other members of the DLG family, including PSD93, SAP97, and SAP102, regulate spine formation or synaptogenesis in vivo. DLG5 is unique among DLG family members because of its large $\mathrm{N}$ terminus with additional protein domains, and it belongs to a distinct branch of the MAGUK protein family. These additional protein domains mediate DLG5 interaction with $\beta$-catenin and regulate the subcellular localization of $N$-cadherin, which is important for determining cell polarity in epithelial cells (Nechiporuk et al., 2007) and, as we show here, synaptogenesis in neurons.

\section{$\mathrm{N}$-cadherin regulation of dendritic spine formation}

Previous studies in cultured hippocampal neurons identified $\beta$-catenin and $N$-cadherin as important regulators of spine morphogenesis and synaptogenesis (Togashi et al., 2002; Okuda et al., 2007; Saglietti et al., 2007). The molecular pathways that regulate $\mathrm{N}$-cadherin subcellular localization in other developmental processes have begun to be elucidated. For example, Rab-dependent endocytic pathways regulate $\mathrm{N}$-cadherin trafficking during cortical neuronal migration (Kawauchi et al., 2010). However, the mechanism by which $N$-cadherin is localized to dendritic spines and promotes spine formation is poorly understood. In hippocampal neurons, afadin, a Ras/Rap effector, promotes $N$-cadherin recruitment to dendritic spines (Beaudoin et al., 2012). Here, we identify DLG5 as a critical molecule for promoting cell surface localization of $\mathrm{N}$-cadherin in cortical neurons. Although we cannot formally exclude the possibility that DLG5 regulates dendritic spine formation through other molecular interactions, suppression of the spine deficit in $D \lg 5^{\mathrm{LP} / \mathrm{LP}}$ neurons by $\mathrm{N}$-cadherin overexpression, coupled with genetic interactions between $D L G 5^{\mathrm{LP}}$ and $\mathrm{N}$-cad ${ }^{\text {null }}$ in vivo, strongly suggest that $\mathrm{N}$-cadherin is a key effector of DLG5 function in dendritic spine formation. In contrast to previous studies in which $N$-cadherin function perturbed by overexpressing an extracellular domaindeleted $\mathrm{N}$-cadherin resulted in altered dendritic spine morphology in cultured hippocampal neurons (Togashi et al., 2002), we did not observe a significant alteration in Dlg $5^{\mathrm{LP} / \mathrm{LP}}$ mutant cortical neuron dendritic spine morphology in vivo. This discrepancy may result from differences in the methods used to perturb neuronal $\mathrm{N}$-cadherin function and/or differences between cortical and hippocampal neurons. A key early event in the elaboration of dendritic spines and synaptogenesis is the stabilization of 

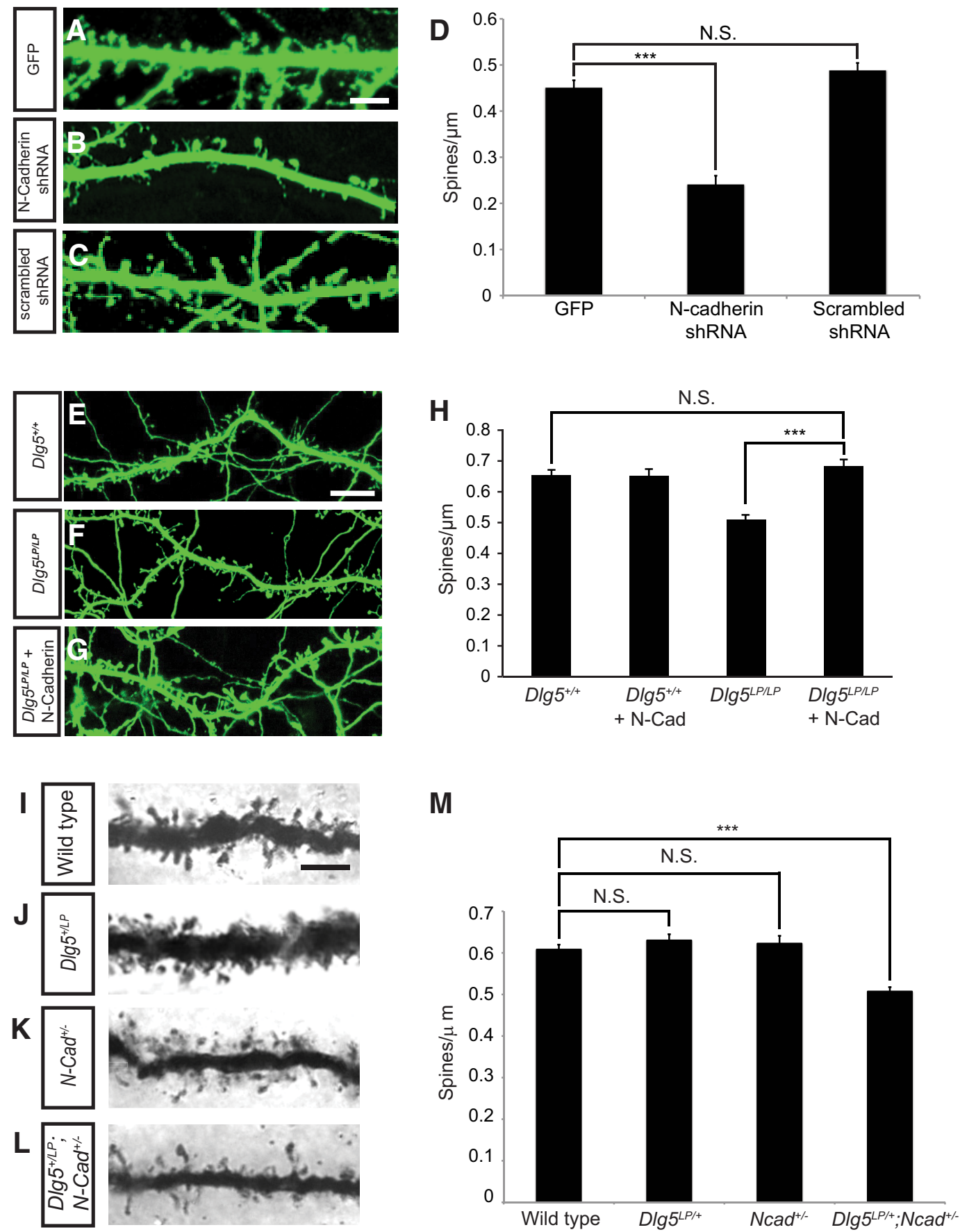

Figure 9. DLG5 regulation of dendritic spine development requires $N$-cadherin. $A-C$, Cortical neurons derived from E13.5 WT embryos were transfected with constructs expressing GFP (A), $N$-cadherin shRNA and GFP $(\boldsymbol{B})$, or scrambled shRNA and GFP $(\boldsymbol{C})$ at 8 DIV and cultured for a total of 21 DIV. N-cadherin knockdown causes a significant decrease in dendritic spine density, whereas scrambled shRNA has no effect. $D$, Quantification of dendritic spine density in cortical neurons at 21 DIV (GFP: $0.451 \pm 0.016$ spines $/ \mu \mathrm{m} ; N$-cadherin shRNA: $0.241 \pm 0.019$ spines $/ \mu \mathrm{m}$; scrambled shRNA: $0.488 \pm 0.016$ spines $/ \mu \mathrm{m}$ ). Number of neurons quantified: $n=24$ for GFP from 3 independent cultures, $n=24$ for $N$-cadherin shRNA from 3 independent cultures, and $n=10$ for scrambled shRNA from 3 independent cultures. Error bar represents SEM. ${ }^{* * *} p<0.001$ by two-tailed Student's $t$ test. $E-G$, Cortical neurons from E13.5 Dlg $5^{+/+}$and Dlg ${ }^{\text {LP/LP }}$ embryos were transfected with constructs expressing GFP or GFP-N-cadherin at 8DIV and then cultured for a total of 21DIV. $N$-cadherin overexpression rescues the dendritic spine density defect in Dlg 5 LP/LP

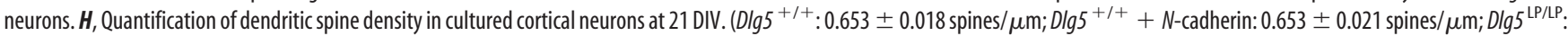
$0.509 \pm 0.015$ spines $/ \mu \mathrm{m} ; D / g 5^{L P / L P}+N$-cadhrin: $0.684 \pm 0.021$ spines $\left./ \mu \mathrm{m}\right)$. Number of neurons quantified: $n=27$ from 3 independent cultures for $D / g 5^{+/+}, n=27$ from 3 independent cultures for Dlg $5^{+/+}+N$-cadherin, $n=27$ from 3 independent cultures for Dlg $5^{\text {LP/LP }}$, and $n=27$ from 3 independent cultures for Dlg $5^{\text {LP/LP }}+N$-cadherin. Error bar represents SEM. ${ }^{* * *} p<$ 0.001 , N.S. $p=0.27$ by two-tailed Student's $t$ test. $I-L$, Layer V pyramidal neurons from wild-type $(\boldsymbol{l})$, Dlg $5^{\text {LP/+ }}(\boldsymbol{J}), \mathrm{Ncad}^{+/-}(\boldsymbol{K})$, and Dlg5 ${ }^{\mathrm{LP} /+} ; \mathrm{Ncad}^{+/-}(\boldsymbol{L})$ brains were examined by Golgi staining at P28. Dlg $5^{\mathrm{LP} /+} ; \mathrm{Ncad}^{+/-}$neurons show a significant reduction in dendritic spine density, whereas $\mathrm{Dlg} 5^{\mathrm{LP} /+}$ and $\mathrm{Ncad}^{+/-}$neurons have normal spine density. $M$, Quantification of dendritic spine density in layer V pyramidal neurons. (Wild-type: $0.608 \pm 0.012$ spines $/ \mu \mathrm{m} ; D \operatorname{Dlg} 5^{\mathrm{L} /+}: 0.63 \pm 0.015$ spines $/ \mu \mathrm{m} ; \mathrm{Ncad}^{+/-}: 0.622 \pm 0.019 \mathrm{spines} / \mu \mathrm{m} ; \mathrm{Dlg} 5^{\mathrm{LP} /+} ; \mathrm{Ncad}{ }^{+/-}$: $0.507 \pm 0.011$ spines $/ \mu \mathrm{m})$. The number of neurons quantified: $n=30$ neurons from 3 brains for wild-type, $n=30$ neurons from 3 brains for Dlg $5^{\mathrm{LP} /+}, n=30$ neurons from 3 brains for Ncad ${ }^{+/-}$,

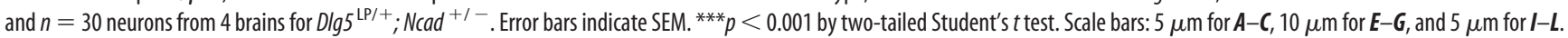


trans-synaptic contacts mediated by cell surface proteins. The availability of cell adhesion molecules at the neuronal cell-surface could therefore determine whether trans-synaptic contacts successfully develop into synapses. In addition to providing transsynaptic adhesion, $\mathrm{N}$-cadherin may also regulate cytoskeletal dynamics in dendritic spines through multiple signaling pathways, including signaling by the Rho family of GTPases and PI3 kinase (Arikkath and Reichardt, 2008; Stepniak et al., 2009). Future work will determine whether these, or other, signaling pathways are affected by loss of DLG5.

In addition to $\beta$-catenin, DLG5 has been shown to interact with syntaxin-4 (Nechiporuk et al., 2007). Syntaxin-4 is a postsynaptic t-SNARE (target-Soluble NSF-Attachment Protein Receptor) that is involved in the exocytosis of AMPA-receptorcontaining vesicles at the postsynaptic membrane during elevated synaptic activity (Kennedy et al., 2010). Future work will determine whether DLG5 promotes surface localization of catenin-cadherin complexes during synaptogenesis through interactions with syntaxin-4.

\section{Role of the DLG5 SH3 domain in neurons}

Using a forward genetic screen, we have isolated a novel Dlg5 allele, $D \lg 5^{\mathrm{LP}}$, that harbors an L1642P substitution in the DLG5 SH3 domain. This single amino acid substitution in the DLG5 SH3 domain disrupts DLG5 protein functions required for dendritic spine formation both in vitro and in vivo. The severity of the hydrocephalus and dendritic spine deficits in the $D \lg 5^{\text {LP }}$ point mutant is comparable to that of the null allele despite the presence of DLG5 ${ }^{\mathrm{LP}}$ protein at $\sim 50 \%$ of wild-type protein levels, demonstrating the critical role of the $\mathrm{SH} 3$ domain in normal DLG5 function. In invertebrates, mutations in the SH3 domain of Drosophila Dlg affect septate junction formation and result in lethality (Woods et al., 1996). Here, we provide in vivo evidence for the critical role played by the Dlg5 $\mathrm{SH} 3$ domain in the neuronal function of MAGUK proteins in vertebrates. Previous work on PSD95 indicates that the SH3 domain in MAGUK proteins lacks the characteristic secondary structure required for binding to proline-rich motifs (McGee et al., 2001). Instead, the PSD95 SH3 domain binds to its own GUK domain. It has been proposed that SH3-GUK domain interaction is critical for the formation of PSD95 oligomers that in turn cluster and stabilize channels, celladhesion molecules, and other cell surface proteins (McGee and Bredt, 1999; Colledge et al., 2000; Shin et al., 2000; Tavares et al., 2001; Kim and Sheng, 2004; Bhattacharyya et al., 2009). We show here that the Dlg5L1642P mutation greatly attenuates interaction between the DLG5 SH3 and GUK domains. We propose that loss of protein domain interactions critical for normal DLG5 function, together with a decrease in protein levels, leads to the decrease in synaptic $\beta$-catenin and also cell surface localization of $\mathrm{N}$-cadherin observed in $\mathrm{D} \lg 5^{\mathrm{LP} / \mathrm{LP}}$ mice.

Together, our observations demonstrate that DLG5 is important for dendritic spine formation and synaptogenesis in cortical neurons. On a molecular level, DLG5 regulates synaptogenesis by controlling the subcellular localization of $\beta$-catenin and $N$-cadherin. These observations underscore the importance of MAGUK proteins in dendritic spine formation and define a molecular mechanism that mediates $N$-cadherin cell surface localization during synaptogenesis. The availability of cell adhesion molecules such as $N$-cadherin at the cell surface is a crucial determinant of trans-synaptic contact stabilization and subsequent synapse formation. The identification here of a novel DLG5 neuronal function lends further insight into our understanding of the molecular mechanisms that orchestrate the establishment of neural connectivity.

\section{References}

Arikkath J, Reichardt LF (2008) Cadherins and catenins at synapses: roles in synaptogenesis and synaptic plasticity. Trends Neurosci 31:487-494. CrossRef Medline

Ballesteros-Yáñez I, Benavides-Piccione R, Elston GN, Yuste R, DeFelipe J (2006) Density and morphology of dendritic spines in mouse neocortex. Neuroscience 138:403-409. CrossRef Medline

Beaudoin GM 3rd, Schofield CM, Nuwal T, Zang K, Ullian EM, Huang B, Reichardt LF (2012) Afadin, a Ras/Rap effector that controls cadherin function, promotes spine and excitatory synapse density in the hippocampus. J Neurosci 32:99-110. CrossRef Medline

Béïque JC, Lin DT, Kang MG, Aizawa H, Takamiya K, Huganir RL (2006) Synapse-specific regulation of AMPA receptor function by PSD-95. Proc Natl Acad Sci U S A 103:19535-19540. CrossRef Medline

Bhattacharyya S, Biou V, Xu W, Schlüter O, Malenka RC (2009) A critical role for PSD-95/AKAP interactions in endocytosis of synaptic AMPA receptors. Nat Neurosci 12:172-181. CrossRef Medline

Bhatt DH, Zhang S, Gan WB (2009) Dendritic spine dynamics. Annu Rev Physiol 71:261-282. CrossRef Medline

Bozdagi O, Wang XB, Nikitczuk JS, Anderson TR, Bloss EB, Radice GL, Zhou Q, Benson DL, Huntley GW (2010) Persistence of coordinated longterm potentiation and dendritic spine enlargement at mature hippocampal CAl synapses requires N-cadherin. J Neurosci 30:9984-9989. CrossRef Medline

Carlisle HJ, Fink AE, Grant SG, O’Dell TJ (2008) Opposing effects of PSD-93 and PSD-95 on long-term potentiation and spike timingdependent plasticity. J Physiol 586:5885-5900. CrossRef Medline

Colledge M, Dean RA, Scott GK, Langeberg LK, Huganir RL, Scott JD (2000) Targeting of PKA to glutamate receptors through a MAGUK-AKAP complex. Neuron 27:107-119. CrossRef Medline

Craig AM, Kang Y (2007) Neurexin-neuroligin signaling in synapse development. Curr Opin Neurobiol 17:43-52. CrossRef Medline

Cuthbert PC, Stanford LE, Coba MP, Ainge JA, Fink AE, Opazo P, Delgado JY, Komiyama NH, O’Dell TJ, Grant SG (2007) Synapse-associated protein 102/dlgh3 couples the NMDA receptor to specific plasticity pathways and learning strategies. J Neurosci 27:2673-2682. CrossRef Medline

de Mendoza A, Suga H, Ruiz-Trillo I (2010) Evolution of the MAGUK protein gene family in premetazoan lineages. BMC Evol Biol 10:93. CrossRef Medline

de Wit J, Sylwestrak E, O’Sullivan ML, Otto S, Tiglio K, Savas JN, Yates JR 3rd, Comoletti D, Taylor P, Ghosh A (2009) LRRTM2 interacts with Neurexin1 and regulates excitatory synapse formation. Neuron 64:799-806. CrossRef Medline

El-Husseini AE, Schnell E, Chetkovich DM, Nicoll RA, Bredt DS (2000) PSD-95 involvement in maturation of excitatory synapses. Science 290: 1364-1368. Medline

Elias GM, Funke L, Stein V, Grant SG, Bredt DS, Nicoll RA (2006) Synapsespecific and developmentally regulated targeting of AMPA receptors by a family of MAGUK scaffolding proteins. Neuron 52:307-320. CrossRef Medline

Elston GN, DeFelipe J (2002) Spine distribution in cortical pyramidal cells: a common organizational principle across species. Prog Brain Res 136: 109-133. CrossRef Medline

Feng W, Zhang M (2009) Organization and dynamics of PDZ-domainrelated supramodules in the postsynaptic density. Nat Rev Neurosci 10: 87-99. CrossRef Medline

Hayashi Y, Majewska AK (2005) Dendritic spine geometry: functional implication and regulation. Neuron 46:529-532. CrossRef Medline

Henkemeyer M, Itkis OS, Ngo M, Hickmott PW, Ethell IM (2003) Multiple EphB receptor tyrosine kinases shape dendritic spines in the hippocampus. J Cell Biol 163:1313-1326. CrossRef Medline

Irwin SA, Galvez R, Greenough WT (2000) Dendritic spine structural anomalies in fragile-X mental retardation syndrome. Cereb Cortex 10: 1038-1044. CrossRef Medline

Kaufmann WE, Moser HW (2000) Dendritic anomalies in disorders associated with mental retardation. Cereb Cortex 10:981-991. CrossRef Medline

Kawauchi T, Sekine K, Shikanai M, Chihama K, Tomita K, Kubo K, Nakajima K, Nabeshima Y, Hoshino M (2010) Rab GTPases-dependent endocytic 
pathways regulate neuronal migration and maturation through $\mathrm{N}$-cadherin trafficking. Neuron 67:588-602. CrossRef Medline

Kayser MS, Nolt MJ, Dalva MB (2008) EphB receptors couple dendritic filopodia motility to synapse formation. Neuron 59:56-69. CrossRef Medline

Kennedy MJ, Davison IG, Robinson CG, Ehlers MD (2010) Syntaxin-4 defines a domain for activity-dependent exocytosis in dendritic spines. Cell 141:524-535. CrossRef Medline

Kim E, Sheng M (2004) PDZ domain proteins of synapses. Nat Rev Neurosci 5:771-781. CrossRef Medline

Knobloch M, Mansuy IM (2008) Dendritic spine loss and synaptic alterations in Alzheimer's disease. Mol Neurobiol 37:73-82. CrossRef Medline

Ko J, Fuccillo MV, Malenka RC, Südhof TC (2009) LRRTM2 functions as a neurexin ligand in promoting excitatory synapse formation. Neuron 64: 791-798. CrossRef Medline

Kostetskii I, Li J, Xiong Y, Zhou R, Ferrari VA, Patel VV, Molkentin JD, Radice GL (2005) Induced deletion of the N-cadherin gene in the heart leads to dissolution of the intercalated disc structure. Circ Res 96:346354. CrossRef Medline

Lippman J, Dunaevsky A (2005) Dendritic spine morphogenesis and plasticity. J Neurobiol 64:47-57. CrossRef Medline

McGee AW, Bredt DS (1999) Identification of an intramolecular interaction between the SH3 and guanylate kinase domains of PSD-95. J Biol Chem 274:17431-17436. CrossRef Medline

McGee AW, Dakoji SR, Olsen O, Bredt DS, Lim WA, Prehoda KE (2001) Structure of the SH3-guanylate kinase module from PSD-95 suggests a mechanism for regulated assembly of MAGUK scaffolding proteins. Mol Cell 8:1291-1301. CrossRef Medline

Mendez P, De Roo M, Poglia L, Klauser P, Muller D (2010) N-cadherin mediates plasticity-induced long-term spine stabilization. J Cell Biol 189: 589-600. CrossRef Medline

Merte J, Wang Q, Vander Kooi CW, Sarsfield S, Leahy DJ, Kolodkin AL, Ginty DD (2010b) A forward genetic screen in mice identifies Sema3A(K108N), which binds to neuropilin-1 but cannot signal. J Neurosci 30:5767-5775. CrossRef Medline

Merte J, Jensen D, Wright K, Sarsfield S, Wang Y, Schekman R, Ginty DD (2010a) Sec24b selectively sorts Vangl2 to regulate planar cell polarity during neural tube closure. Nat Cell Biol 12:41-46; sup pp 1-8. CrossRef Medline

Migaud M, Charlesworth P, Dempster M, Webster LC, Watabe AM, Makhinson M, He Y, Ramsay MF, Morris RG, Morrison JH, O’Dell TJ, Grant SG. (1998) Enhanced long-term potentiation and impaired learning in mice with mutant postsynaptic density-95 protein. Nature 396:433-439. CrossRef Medline

Murase S, Mosser E, Schuman EM (2002) Depolarization drives betaCatenin into neuronal spines promoting changes in synaptic structure and function. Neuron 35:91-105. CrossRef Medline

Nechiporuk T, Fernandez TE, Vasioukhin V (2007) Failure of epithelial tube maintenance causes hydrocephalus and renal cysts in Dlg5-/- mice. Dev Cell 13:338-350. CrossRef Medline

Nimchinsky EA, Sabatini BL, Svoboda K (2002) Structure and function of dendritic spines. Annu Rev Physiol 64:313-353. CrossRef Medline

Nomme J, Fanning AS, Caffrey M, Lye MF, Anderson JM, Lavie A (2011) The Src homology 3 domain is required for junctional adhesion molecule binding to the third PDZ domain of the scaffolding protein ZO-1. J Biol Chem 286:43352-43360. CrossRef Medline
Okuda T, Yu LM, Cingolani LA, Kemler R, Goda Y (2007) beta-Catenin regulates excitatory postsynaptic strength at hippocampal synapses. Proc Natl Acad Sci U S A 104:13479-13484. CrossRef Medline

Penzes P, Cahill ME, Jones KA, VanLeeuwen JE, Woolfrey KM (2011) Dendritic spine pathology in neuropsychiatric disorders. Nat Neurosci 14: 285-293. CrossRef Medline

Saglietti L, Dequidt C, Kamieniarz K, Rousset MC, Valnegri P, Thoumine O, Beretta F, Fagni L, Choquet D, Sala C, Sheng M, Passafaro M (2007) Extracellular interactions between GluR2 and N-cadherin in spine regulation. Neuron 54:461-477. CrossRef Medline

Saneyoshi T, Fortin DA, Soderling TR (2010) Regulation of spine and synapse formation by activity-dependent intracellular signaling pathways. Curr Opin Neurobiol 20:108-115. CrossRef Medline

Shin H, Hsueh YP, Yang FC, Kim E, Sheng M (2000) An intramolecular interaction between Src homology 3 domain and guanylate kinase-like domain required for channel clustering by postsynaptic density-95/ SAP90. J Neurosci 20:3580-3587. Medline

Siddiqui TJ, Craig AM (2011) Synaptic organizing complexes. Curr Opin Neurobiol 21:132-143. CrossRef Medline

Spruston N (2008) Pyramidal neurons: dendritic structure and synaptic integration. Nat Rev Neurosci 9:206-221. CrossRef Medline

Stepniak E, Radice GL, Vasioukhin V (2009) Adhesive and signaling functions of cadherins and catenins in vertebrate development. Cold Spring Harb Perspect Biol 1:a002949. CrossRef Medline

Suzuki SC, Takeichi M (2008) Cadherins in neuronal morphogenesis and function. Dev Growth Differ 50:S119-S130. CrossRef Medline

Tada T, Sheng M (2006) Molecular mechanisms of dendritic spine morphogenesis. Curr Opin Neurobiol 16:95-101. CrossRef Medline

Tavares GA, Panepucci EH, Brunger AT (2001) Structural characterization of the intramolecular interaction between the $\mathrm{SH} 3$ and guanylate kinase domains of PSD-95. Mol Cell 8:1313-1325. CrossRef Medline

Togashi H, Abe K, Mizoguchi A, Takaoka K, Chisaka O, Takeichi M (2002) Cadherin regulates dendritic spine morphogenesis. Neuron 35:77-89. CrossRef Medline

Tran TS, Rubio ME, Clem RL, Johnson D, Case L, Tessier-Lavigne M, Huganir RL, Ginty DD, Kolodkin AL (2009) Secreted semaphorins control spine distribution and morphogenesis in the postnatal CNS. Nature 462:1065-1069. CrossRef Medline

Vickers CA, Stephens B, Bowen J, Arbuthnott GW, Grant SG, Ingham CA (2006) Neurone specific regulation of dendritic spines in vivo by post synaptic density 95 protein (PSD-95). Brain Res 1090:89-98. CrossRef Medline

Woods DF, Hough C, Peel D, Callaini G, Bryant PJ (1996) Dlg protein is required for junction structure, cell polarity, and proliferation control in Drosophila epithelia. J Cell Biol 134:1469-1482. CrossRef Medline

Yagi T, Takeichi M (2000) Cadherin superfamily genes: functions, genomic organization, and neurologic diversity. Genes Dev 14:1169-1180. CrossRef Medline

Yoshihara Y, De Roo M, Muller D (2009) Dendritic spine formation and stabilization. Curr Opin Neurobiol 19:146-153. CrossRef Medline

Zhou Z, Hong EJ, Cohen S, Zhao WN, Ho HY, Schmidt L, Chen WG, Lin Y, Savner E, Griffith EC, Hu L, Steen JA, Weitz CJ, Greenberg ME. (2006) Brain-specific phosphorylation of $\mathrm{MeCP} 2$ regulates activity-dependent Bdnf transcription, dendritic growth, and spine maturation. Neuron 52: 255-269. CrossRef Medline 